\title{
Temperature stress and redox homeostasis in agricultural crops
}

\author{
Rashmi Awasthi, Kalpna Bhandari and Harsh Nayyar* \\ Department of Botany, Panjab University, Chandigarh, India
}

\section{Edited by:}

Naser A. Anjum, University of

Aveiro, Portugal

Reviewed by:

Naser A. Anjum, University of

Aveiro, Portugal

Aryadeep Roychoudhury,

St. Xavier's College, India

Yogesh Abrol, Bhagalpur University,

India

*Correspondence:

Harsh Nayyar, Department of

Botany, Panjab University,

Chandigarh 160014, India

e-mail: harshnayyar@hotmail.com
Plants are exposed to a wide range of environmental conditions and one of the major forces that shape the structure and function of plants are temperature stresses, which include low and high temperature stresses and considered as major abiotic stresses for crop plants. Due to global climate change, temperature stress is becoming the major area of concern for the researchers worldwide. The reactions of plants to these stresses are complex and have devastating effects on plant metabolism, disrupting cellular homeostasis and uncoupling major physiological and biochemical processes. Temperature stresses disrupt photosynthesis and increase photorespiration thereby altering the normal homeostasis of plant cells. The constancy of temperature, among different metabolic equilibria present in plant cells, depends to a certain extent on a homeostatically regulated ratio of redox components, which are present virtually in all plant cells. Several pathways, which are present in plant cells, enable correct equilibrium of the plant cellular redox state and balance fluctuations in plant cells caused by changes in environment due to stressful conditions. In temperature stresses, high temperature stress is considered to be one of the major abiotic stresses for restricting crop production worldwide. The responses of plants to heat stress vary with extent of temperature increase, its duration and the type of plant. On other hand, low temperature as major environmental factor often affects plant growth and crop productivity and leads to substantial crop loses. A direct result of stress-induced cellular changes is overproduction of reactive oxygen species (ROS) in plants which are produced in such a way that they are confined to a small area and also in specific pattern in biological responses. ROS (superoxide; $\mathrm{O}_{2}^{-}$, hydroxyl radicals; $\mathrm{OH}^{-}$, alkoxyl radicals and non-radicals like hydrogen peroxide; $\mathrm{H}_{2} \mathrm{O}_{2}$ and singlet oxygen; ${ }^{1} \mathrm{O}_{2}$ ) are highly reactive and toxic and cause damage to proteins, lipids, carbohydrates which ultimately results in oxidative stress. ROS may also serve as signaling molecules in mediating important signal transduction pathways that coordinate an astonishing range of diverse plant processes under temperature stress. To counter temperature induced oxidative stress, plants upregulate a variety of enzymatic and non-enzymatic antioxidants which are also information-rich redox buffers and important components of redox signaling that interact with biomembrane-related compartments. They provide essential information on cellular redox state, and regulate gene expression associated with stress responses to optimize defense and survival, stress acclimation and tolerance. The work done by various researchers has explored a direct link between ROS scavenging and plant tolerance under temperature extremes in various crops which include legumes, cereals, oil crops and vegetables. There is ample need to develop temperature tolerance in crop plants by exploring suitable strategies to manage oxidative stress and maintain cellular redox state. Here, we summarize the studies linking ROS and temperature stress in plants, their generation and site of production, role of ROS as messengers as well as inducers of oxidative damage and strategies for the development of temperature stress tolerance involving redox homeostasis in various agricultural crops.

Keywords: temperature stress, oxidative damage, legumes, cereals, homeostasis

\section{INTRODUCTION}

Plants are constantly subjected to different environmental conditions, which cause alterations in their metabolism in order to maintain a steady-state balance between energy generation and consumption and also in their redox state (Suzuki et al., 2011). Several environmental conditions result in stress in plants to adversely affect the metabolism, growth and development and may even lead to death under long-term exposures 
(Boguszewska and Zagdanska, 2012). Various abiotic stresses include drought, salt, low/high temperature, flooding and anaerobic conditions, which limit crop growth and productivity (Lawlor and Cornic, 2002). Among all the stresses, temperature stresses (cold or heat) can have devastating effects on plant growth and metabolism, also leading to alterations in redox state of the plant cell which is one of the important consequences of the fluctuating environment conditions (Suzuki and Mittler, 2006; Suzuki et al., 2011; Bita and Gerats, 2013). A delicate balance exists between multiple pathways residing in different organelles of plant cells, known as cellular homeostasis (Kocsy et al., 2013). This coordination between different organelles may be disrupted during temperature stresses due to variation in temperature optimum in different pathways within cells (Hasanuzzaman et al., 2013a). The constancy of temperature, among different metabolic equilibria present in plant cells, depends to a certain extent on a homeostatically-regulated ratio of redox components, which are present virtually in all plant cells (Suzuki et al., 2011). Several pathways, which are present in plant cells enable correct equilibrium of the plant cellular redox state and balance fluctuations in plant cells caused by changes in environment due to stressful conditions which are otherwise sensitive to changes in environmental conditions, especially temperature stresses (Foyer and Noctor, 2005, 2012; Suzuki et al., 2011). Plant Redox changes result in modification or induction of various physiological and biochemical processes through regulatory networks including ROS and antioxidants by reprogramming transcriptome which include the set of all RNA molecules, proteome including all proteins expressed by genome and metabolome such as metabolic intermediates, hormones and other signaling molecules etc. (Foyer and Noctor, 2009). Furthermore, reactions of plants to temperature stresses are complex and have adverse effects on plant metabolism by disrupting cellular homeostasis and uncoupling major physiological and biochemical processes (Hasanuzzaman et al., 2013a; Hemantaranjan et al., 2014). These stresses alter the normal homeostasis of plant cells by disrupting photosynthesis and increasing photorespiration (Noctor et al., 2007). A direct result of stress-induced cellular changes is overproduction of reactive oxygen species (ROS) in plants which are produced in such a way that they are confined to a small area and also in specific pattern in biological responses. The production of ROS is an inevitable consequence of aerobic metabolism during stressful conditions (Bhattacharjee, 2012). ROS are highly reactive and toxic, affecting various cellular functions in plant cells through damage to nucleic acids, protein oxidation, and lipid peroxidation, eventually resulting in cell death (Figure 1) (Bhattacharjee, 2005; Amirsadeghi et al., 2006; Suzuki et al., 2011; Tuteja et al., 2012). ROS toxicity due to stresses is considered to be one of the major causes of low crop productivity worldwide (Vadez et al., 2012).

ROS system consists of both free radicals including superoxide $\left(\mathrm{O}_{2}^{-}\right)$, hydroxyl radicals $\left(\mathrm{OH}^{-}\right)$, alkoxyl radicals and non-radicals like hydrogen peroxide $\left(\mathrm{H}_{2} \mathrm{O}_{2}\right)$ and singlet oxygen $\left({ }^{1} \mathrm{O}_{2}\right)$ (Gill and Tuteja, 2010). During stress conditions, these species are always formed by the leakage of electrons from the electron transport activities of chloroplasts, mitochondria, and plasma membranes or also as a by-product of various metabolic pathways localized in different cellular compartments (Del Rio et al., 2006; Gill and Tuteja, 2010; Sharma et al., 2012; Figure 2). Depending upon their concentrations, ROS play dual role as both deleterious and beneficial species in plants (Kotchoni and Gachomo, 2006). At low/moderate concentrations, ROS act as second messengers in various intercellular signaling pathways that mediate many responses in plants, thus regulating cellular redox state whereas at higher concentrations they have detrimental effects on plant growth (Mittler, 2002; Torres et al., 2002; Yan et al., 2007; Miller et al., 2008; Sharma et al., 2012). Plants have various metabolic and developmental processes which are regulated by cross-talk between ROS and hormones (Kocsy et al., 2013). ROS can activate the synthesis of many plant hormones such as brassinosteroids, ethylene, jasmonate and salicylic acid (Ahmad et al., 2010). In contrast, some hormones such as auxins, ABA, salicylic acid can also result in ROS generation (Figure 3). The redox state of the cell may be affected by plant hormones through transcriptional stimulation of genes coding for molecules involved in redox system (Laskowski et al., 2002). Various metabolic and developmental processes which involve interaction between ROS and hormones in plants include stomatal closure (Yan et al., 2007; Neill et al., 2008), programmed cell death (Bethke and Jones, 2001), gravitropism (Jung et al., 2001), control of root apical meristem organization (Jiang and Feldman, 2003) and acquisition of tolerance to both biotic and abiotic stresses (Torres et al., 2002; Miller et al., 2008).

These ROS are continuously reduced/scavenged by plant antioxidative defense systems which maintain them at certain steady-state levels under stressful conditions (Tuteja et al., 2012). An efficient anti-oxidative system comprising of the nonenzymatic as well as enzymatic antioxidants is involved in scavenging or detoxification of excess ROS (Noctor et al., 2007; Sharma et al., 2012). Various enzymatic antioxidants comprise of superoxide dismutase (SOD), catalase (CAT), glutathione peroxidase (GPX), enzymes of ascorbate-glutahione (AsA-GSH) cycle such as ascorbate peroxidase (APX), monodehydroascorbate reductase (MDHAR), dehydroascorbate reductase (DHAR), and glutathione reductase (GR) (Noctor and Foyer, 1998; Foyer and Noctor, 2003) whereas Non-enzymatic antioxidants include phenolics, ascorbate (AsA), glutathione (GSH), carotenoids, and tocopherols (Apel and Hirt, 2004; Gill and Tuteja, 2010). Increased activities of many antioxidant enzymes have been observed in plants to combat oxidative stress induced by various environmental stresses and also to maintain cellular homeostasis (Blokhina et al., 2003; Almeselmani et al., 2006). Maintenance of a high antioxidant capacity to scavenge the toxic ROS has been linked to increase in tolerance of plants to these environmental stresses (Suzuki et al., 2011; Hasanuzzaman et al., 2013a). Transgenic lines with altered levels of antioxidants have been developed for improving stress-induced oxidative stress tolerance in various crop plants (Chen et al., 2010; Hasanuzzaman et al., 2013b). Transgenics developed with concurrent expression of multiple antioxidant enzymes are found to have more tolerance to multiple environmental stresses compared to those transformed with one or two genes (Suzuki et al., 2011; Sharma et al., 2012). 


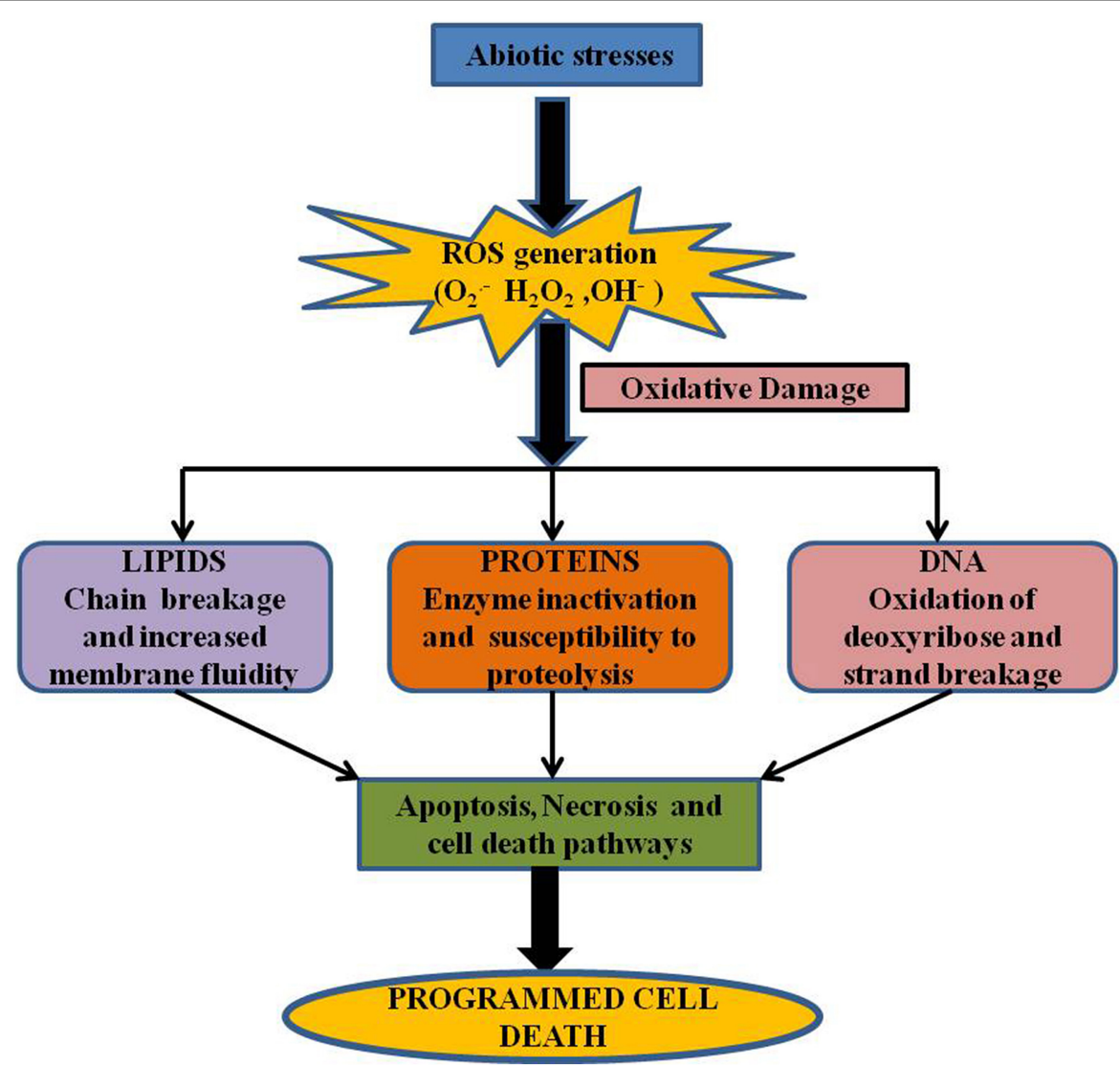

FIGURE 1 | Reactive oxygen species induced oxidative damage to lipids, proteins and nucleic acids. Oxidative stress, induced by the accumulation of reactive oxygen species (ROS) such as $\mathrm{O}_{2}^{--}, \mathrm{H}_{2} \mathrm{O}_{2}$ and $\mathrm{OH} \cdot$, which can bring out a range of stress responses. Exposure of cells to severe oxidative stress can elicit lethal response pathways such as apoptosis, necrosis, and possibly other forms of cell death pathways which can ultimately lead to programmed cell death.

\section{TEMPERATURE STRESSES}

Temperature stress is becoming a major area of concern for plant scientists due to climate change, affecting crop production worldwide (Hasanuzzaman et al., 2013b). Every plant species has optimum temperature limits for its growth and development and abnormal temperatures have devastating effects on plant growth and metabolism (Yadav, 2010; Suzuki et al., 2011; Hasanuzzaman et al., 2012a, 2013b; Kumar et al., 2013a,b). According to global climate change scenarios, high temperature stress is considered as a critical factor for plant growth and productivity and the plant responses to high temperature vary with the extent of temperature increase, its duration and type of plant (Mittler, 2006; Wahid et al., 2007; Hasanuzzaman et al., 2012a). High temperature may adversely affect vital physiological processes like photosynthesis, respiration, water relations and membrane stability and also modulate levels of hormones, primary and secondary metabolites (Hemantaranjan et al., 2014). Furthermore, for the duration of plant ontogeny, enhanced expression of a variety of heat shock and stress-related proteins and production of ROS constitute the major plant responses to heat stress (Saidi et al., 2011; Hasanuzzaman et al., 2013a; Hemantaranjan et al., 2014). Higher ROS concentrations are associated with lipid peroxidation; mainly cellular membranes are particularly susceptible to oxidative damage (Sharkey, 2005; Suzuki and Mittler, 2006). In addition, acquired thermotolerance, i.e., the ability of plants to develop heat tolerance was shown to be mediated in plants by enhancing cellular mechanisms that prevent oxidative damage under high temperature conditions in crops (Larkindale and Huang, 2004; Suzuki and Mittler, 2006). According to various studies, different types of signal transduction pathways and defense mechanisms due to heat stress are involved in sensing of ROS and helpful in providing thermotolerance to crop plants (Figure 4; Apel and Hirt, 2004; Kreslavski et al., 2012; Hasanuzzaman et al., 2013b; Miura and Furumoto, 2013). In contrast, low temperature stress or cold stress is another factor that often affects plant growth and productivity and leads to substantial crop losses (Croser et al., 2003; Yadav et al., 2004; Beck et al., 2007; Yadav, 2010; Sanghera et al., 2011; Miura and Furumoto, 2013). Cold stress or low temperature, which includes both chilling stress $\left(<20^{\circ} \mathrm{C}\right)$ and freezing stress $\left(<0^{\circ} \mathrm{C}\right)$ is one of the most significant abiotic stresses of agricultural plants, affecting plant development and yield and consequently reducing crop production (Lang et al., 2005; Thakur et al., 2010). It results in micro-organelle disruption, phase transition in cell membrane lipids and generation of ROS (Kim et al., 2013). It also induces cascades of alterations in metabolic pathways which 


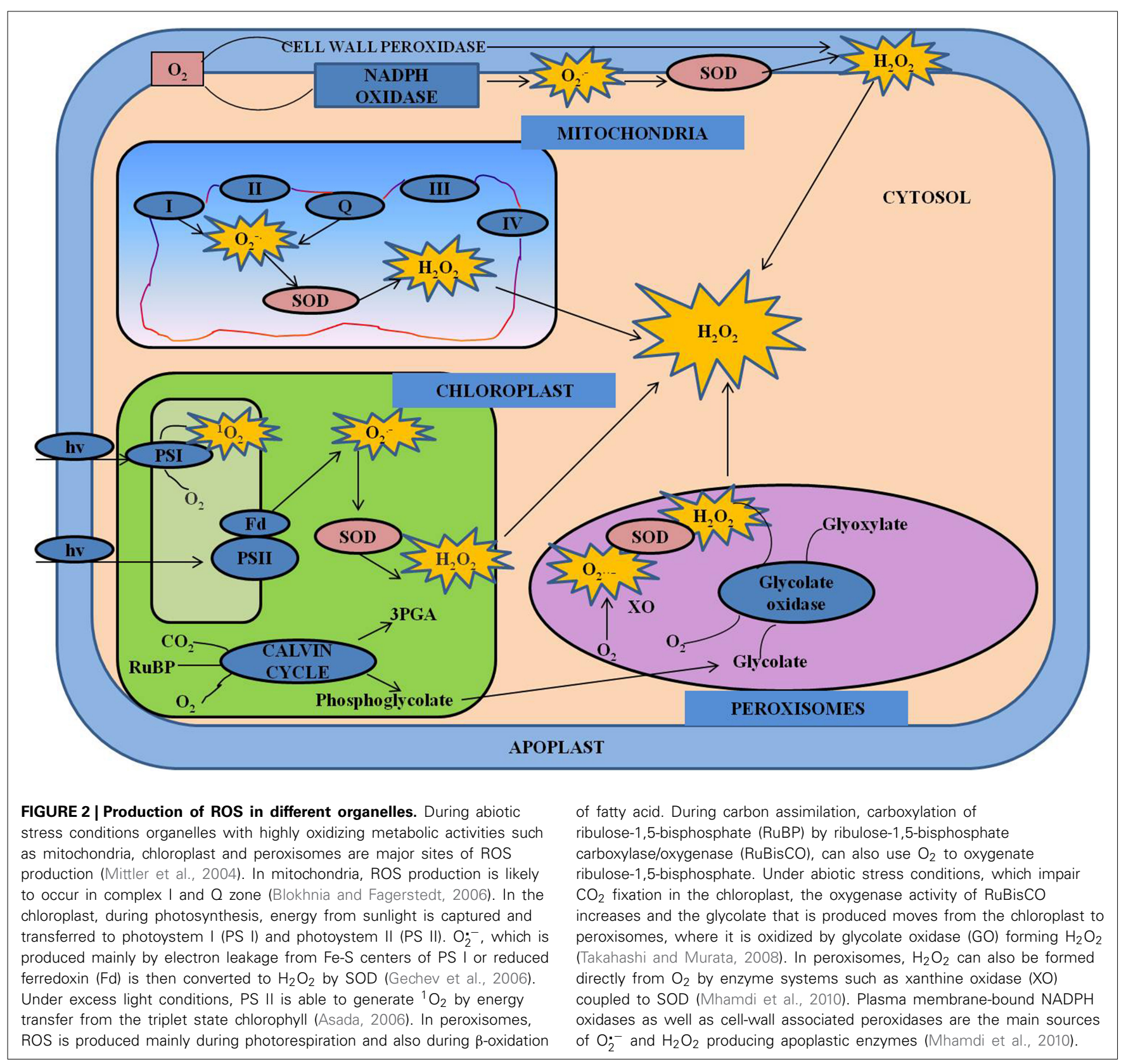

include changes in membrane fatty acid composition, activity of antioxidant enzymes, gene regulation and changes in redox state (Shahandashti et al., 2014). According to various reports, mechanisms governing the temperature response in higher plants are being extensively probed to improve the cold tolerance in agricultural crops (Chinnusamy et al., 2007; Thakur et al., 2010). Various cellular changes, which are induced by either high temperature or low temperature lead to the overproduction of toxic compounds, especially ROS that result in oxidative stress (Mittler, 2002). ROS have toxic potential effects as they can induce protein oxidation, DNA damage, lipid peroxidation of membranes (malondialdehyde content) and destruction of pigments (Apel and Hirt, 2004; Xu et al., 2006; Hasanuzzaman et al., 2012a), however plants have evolved variety of responses to extreme temperatures that help in minimizing damages and provide cellular homeostasis (Kotak et al., 2007). Direct link exists between ROS scavenging and plant stress tolerance under temperature stress conditions which is often related to enhanced activities of antioxidative defense enzymes that confers stress tolerance to either high temperature or low temperature stress (Huang and Guo, 2005; Almeselmani et al., 2009).

\section{TEMPERATURE STRESSES AND OXIDATIVE DAMAGE IN CROPS \\ LEGUMES}

Grain legumes are important food commodities and also the essential components of crop rotation throughout the world (McDonald and Paulsen, 1997). High temperature stress is 


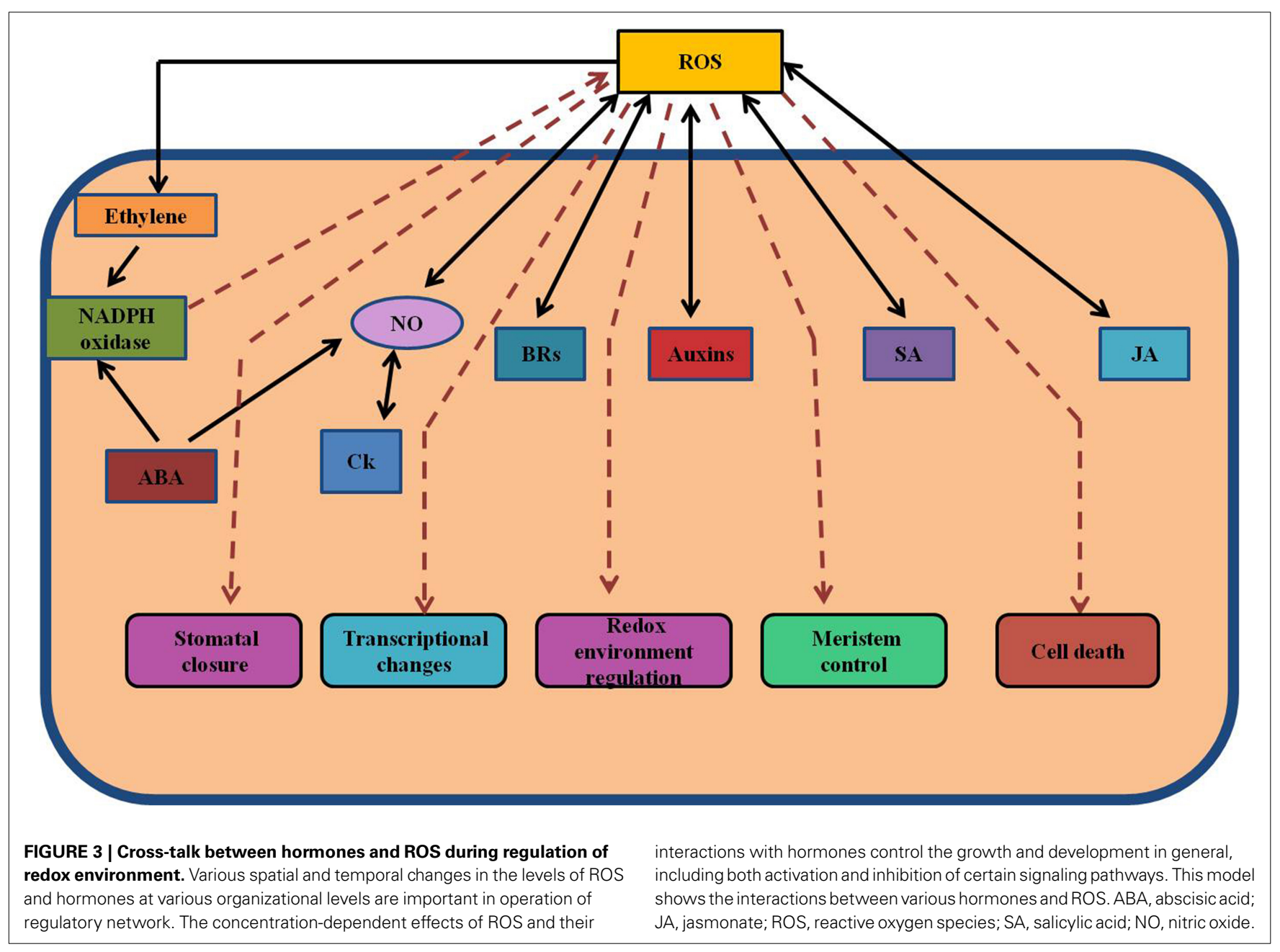

predicted to occur more frequently further affecting various aspects of leguminous crops (Hatfield et al., 2011; Ibrahim, 2011; Reddy et al., 2012). ROS produced during extreme temperature conditions have been demonstrated to cause oxidative damage leading to cellular injury in legumes (Apel and Hirt, 2004). In Phaseolus vulgaris, increased $\mathrm{H}_{2} \mathrm{O}_{2}$ content was observed at 46$48^{\circ} \mathrm{C}$, which further led to lipid peroxidation in membranes and accumulation of malondialdehyde (MDA) (Nagesh and Devaraj, 2008; Kumar et al., 2011). In chickpea (Cicer arietinum), at $40 / 30^{\circ} \mathrm{C}$ (day/night) temperatures under controlled conditions, symptoms of heat stress arise in the form of chlorosis of leaves, membrane damage and loss of viability of tissues. The damage to the plants becomes intensive at $45 / 35^{\circ} \mathrm{C}$ (Kumar et al., 2011) that was attributed to increased oxidative damage as lipid peroxidation and $\mathrm{H}_{2} \mathrm{O}_{2}$ content, which was relatively greater in heat-sensitive genotypes, especially at $40 / 30$ and $45 / 35^{\circ} \mathrm{C}$. According to Kaushal et al. (2011), oxidative damage, measured as lipid peroxidation and hydrogen peroxide concentration, increased with heat stress $\left(45 / 40^{\circ} \mathrm{C}\right)$, pertinently lipid peroxidation was found to increase to a greater extent indicating membrane injury. Also, decrease in the activities of enzymatic antioxidants (SOD, CAT, APX, GR) was observed, which was due to their denaturation at higher temperature, i.e., $45 / 40^{\circ} \mathrm{C}$. When compared with other grain legumes such as pigeonpea, groundnut and soybean, chickpea was the most sensitive in terms of oxidative damage, membrane thermostability and PSII function (Srinivasan et al., 1999). In another legume, Mungbean (Vigna radiata $\mathrm{L}$ ), which is a summer-season crop, the seedlings exposed to higher temperature of $50^{\circ} \mathrm{C}$ for $2 \mathrm{~h}$ (lethal temperature) as well as pretreated with $40^{\circ} \mathrm{C}$ for $1 \mathrm{~h}$, were analyzed for MDA content and antioxidative enzymes. The results showed that the growth in lethal temperature was extremely poor which improved when pre-treatment of $40^{\circ} \mathrm{C}$ was applied before $50^{\circ} \mathrm{C}$. The content of MDA in seedlings treated with lethal temperature was highest at any harvest, which reduced when seedlings were pre-treated with $40^{\circ} \mathrm{C}$ prior to lethal stress (Mansoor and Naqvi, 2013). These observations were attributed to heat acclimation, which improved the antioxidant defense. In soybean, heat stress enhanced membrane permeability and electrolyte leakage as a result of oxidative damage, which in turn reduced the ability of the plasma membrane to retain solutes and water (Lin et al., 1984). In another related study, increased membrane lipid peroxidation due to heat stress was noticed which aggravated the membrane injury in soybean (Glycine max) (Tan et al., 2011). Also, the crop exposed to day/night temperature of $38 / 28^{\circ} \mathrm{C}$ for 14 days at flowering stage showed damage to chloroplast and thylakoids membranes (Tan et al., 2011). Heat induced 


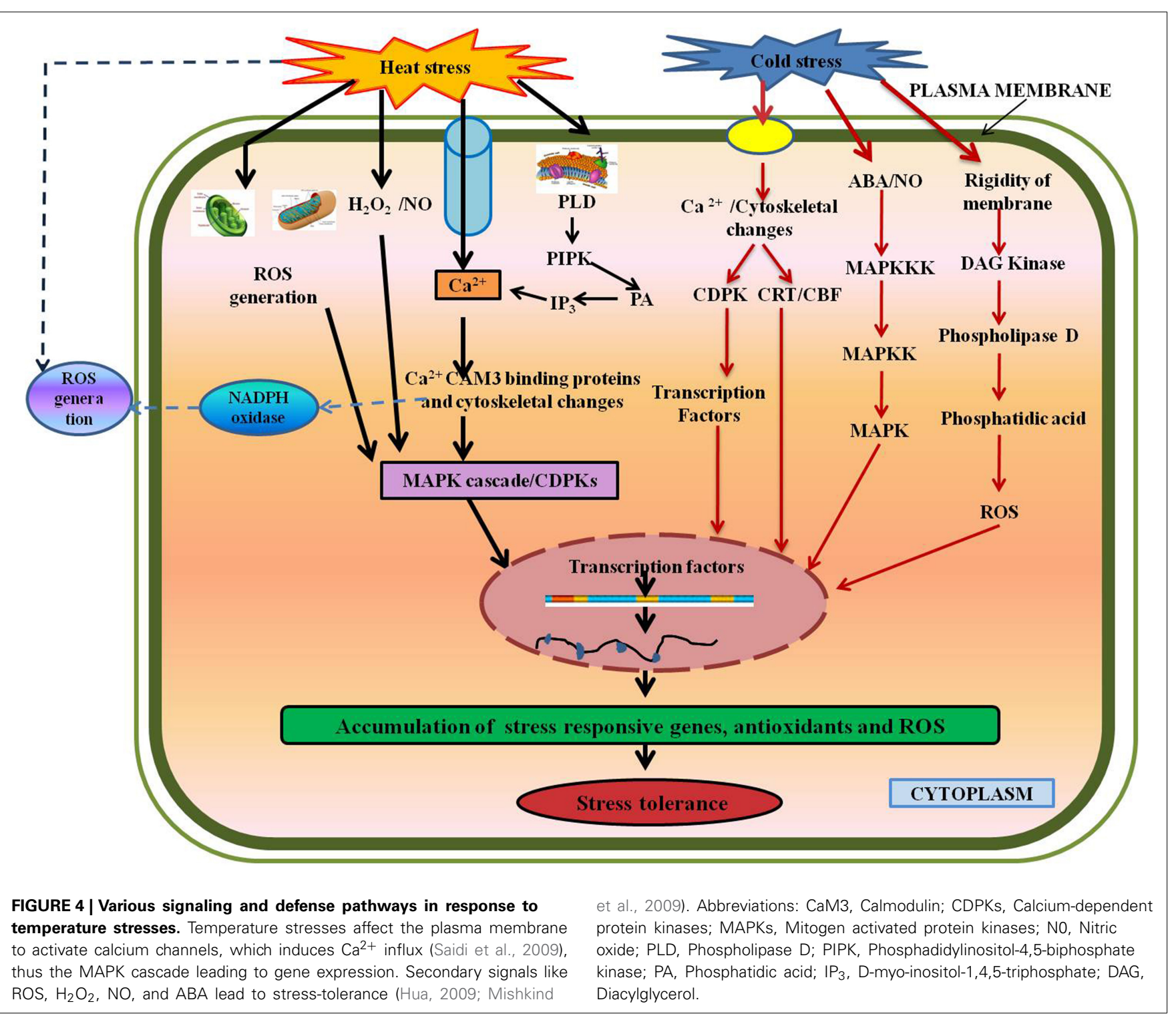

membrane damage has been reported in broad bean (Hamada, 2001) and soybean (Djanaguiraman et al., 2011). ROS arising out from heat stress were implicated as primary agents causing oxidative injury in all these studies.

Many economically important legumes are sensitive to temperature below $15^{\circ} \mathrm{C}$ (Ouellet, 2007). Stressful low temperatures lead to disruption of respiration by affecting respiratory rate which may at first increase in response to chilling (Kaur et al., 2008) but on continued exposure, it decreases (Munro et al., 2004) or plants may resort to some alternative respiratory pathway as found in case of mungbean (Vigna radiata) and pea leaves (Gonzalez-Meler et al., 1999). Besides these implications, other harmful effects of low temperature reported are loss of membrane fluidity and rigidification (Vigh et al., 2007; Jewell et al., 2010), generation of ROS (Wang et al., 2009a,b; Turan and Ekmekci, 2011). At metabolic levels, chilling stress negatively affects photosynthesis as described in pea (Pisum sativum; Guilioni et al., 1997), mungbean (Vigna radiate; Gonzalez-Meler et al., 1999), beans (Phaseolus vulgaris; Tsonev et al., 2003), chickpea (Cicer arietinum; Nayyar et al., 2005b; Berger et al., 2006), pigeon pea (Cajanus cajan; Sandhu et al., 2007), faba beans (Torres et al., 2011), soybean (Ohnishi et al., 2010; Board and Kahlon, 2012). The loss of membrane integrity is the primary damage of chilling temperatures due to oxidative stress, which results in the production of $\mathrm{H}_{2} \mathrm{O}_{2}$ and MDA content due to lipid peroxidation (Nayyar and Chander, 2004; Tambussi et al., 2004; Nayyar et al., 2005a,b,c,d). In mungbean, exposure of plants to low temperature showed damage to PSII, further reducing photochemical efficiency due to photoinhibition and damage to chloroplast (Saleh, 2007). It also resulted in swelling of plastids and accumulation of lipid drops, ultimately leading to disorganization of entire plastid (Ishikawa, 1996). In mungbean, 5 days old seedlings subjected to stressful low temperature $\left(4^{\circ} \mathrm{C}\right.$ for 2 days) showed irreversible chilling injury as evident from increased electrolyte leakage contents due to membrane damage (Chang et al., 2001). Chillinginflicted membrane damage was also reported in broad bean 
(Hamada, 2001). Chickpea is a chilling- sensitive crop and its productivity is adversely affected by chilling temperatures as chilling stress is the principal cause for crop reduction in chickpea (Nayyar et al., 2005b). Increased electrolyte leakage was reported in chickpea under cold stress $\left(5 / 13^{\circ} \mathrm{C}\right.$ mean min. and max. temperature), thereby indicating altered membrane permeability, structural disintegration and membrane injury in chickpea (Croser et al., 2003; Nayyar et al., 2005a). For chickpea, same results were observed in various studies conducted by different researchers (Bakht et al., 2006; Turan and Ekmekci, 2011; Shahandashti et al., 2014). The decrease in photosynthetic capacity was observed in soybean (Glycine max), which was partly due to chilling-associated oxidative damage to chloroplast components. Also, the lipid peroxidation and oxidative damage to thylakoid proteins were observed in leaves of soybean exposed to chilling stress under light (Tambussi et al., 2004). In another study of Glycine max, a much larger reduction was observed in the speed of germination of radical length at chilling temperature, which was probably due to decrease in activity of numerous enzymes involved in degradation of seed storage reserves, transport of degradation products and their metabolism in the embryonic roots. This decrease in enzymatic activity was resulted due to generation of ROS induced by chilling stress (Borowski and Michalek, 2014).

\section{CEREALS}

High temperature stress is considered as a key stress factor with high potential impact on crop yield of cereals (Hasanuzzaman et al., 2013a). On the other hand, long term exposure of cereals to low temperature showed reduction in photochemical efficiency of PSII due to photoinhibition and damage to chloroplast (Kratsch and Wise, 2000; Hasanuzzaman et al., 2013a). One of the major consequences of high temperature stress in cereals is oxidative damage caused by imbalance of metabolic processes such as photosynthesis and respiration either by increasing the ROS or by decreasing the oxygen radical scavenging ability in the cell (Mittler, 2002; Wormuth et al., 2007; Barnabas et al., 2008). High temperature stress leads to the peroxidation of membrane lipids leading to the production of malondialdehyde (MDA), which is a good indicator of free radical damage to cell membranes (Hasanuzzaman et al., 2013a,b). Heat-stress-induced membrane peroxidation and aggravated membrane injury was observed in wheat (Savicka and Skute, 2010), rice and maize (Kumar et al., 2012c) and sorghum (Tan et al., 2011). High temperature stress in sorghum (Hordeum vulgare) resulted in lipid peroxidation of membranes to cause membrane injury. Membrane damage and MDA content increased by 110 and $75 \%$, respectively which was due to increased $\mathrm{H}_{2} \mathrm{O}_{2}$ and $\mathrm{O}_{2}^{-}$content (Mohammed and Tarpley, 2010). High temperature stress decreased antioxidant enzyme activities and increased oxidant production in sorghum (Djanaguiraman et al., 2010). In this study, SOD, CAT and POX activities were decreased during heat stress (22, 15, and $25 \%$ lower than control plants) and the inhibition of all antioxidant enzymes in heat-stressed plants relative to control plants indicated inactivation of all antioxidant enzymes by heat stress. In wheat seedlings, gradual increase in $\mathrm{H}_{2} \mathrm{O}_{2}$ content was observed $\left(0.5,0.58,0.78\right.$, and $\left.1.1 \mu \mathrm{mol} \mathrm{g}{ }^{-1} \mathrm{FW}\right)$ in response to different heat shock treatments of $22,30,35$, and $40^{\circ} \mathrm{C}$ for the time period of $2 \mathrm{~h}$ (Kumar et al., 2012a). Oxidative damage due to ROS production during long term exposure to high temperature led to changes in MDA content and $\mathrm{O}_{2}^{-}$production which were observed at two growth stages, i.e., early stages (4-dayold) and late stages (7-day-old) of wheat (Triticum aestivum) seedlings development (Savicka and Skute, 2010; Cossani and Reynolds, 2012). In another study on wheat, increased MDA concentration was observed in first leaf of wheat seedlings during high temperature stress conditions, which is due to the increased production of superoxide radical $\left(\mathrm{O}_{2}^{-}\right)$(Bohnert et al., 2006). According to Kumar et al. (2012c), high temperature of $40 / 35^{\circ} \mathrm{C}$ (day/night temperature) resulted in 1.8-fold and 1.2- to 1.3-fold increase of MDA content in rice and maize genotypes, respectively over the control treatment. A further increase of MDA content was observed at $45 / 40^{\circ} \mathrm{C}$, in both the crops, where an increase of 2.2- to 2.4-fold was noticed in rice genotypes compared to 1.7 -fold increase in maize genotypes. With rise in temperature to $45 / 40^{\circ} \mathrm{C}$, oxidative damage increased further in rice genotypes (Kumar et al., 2012c; Theocharis et al., 2012; Yang et al., 2012).

Cold stress, especially the chilling stress in cereal crops, is one major form of stress which affects the crop growth and yield (Hasanuzzaman et al., 2013a). Cold stress-induced tissue dehydration further leads to membrane disintegration, reduced growth and development of plants in maize which was due to the accumulation of MDA content as a result of lipid peroxidation in membranes (Farooq et al., 2009; Yadav, 2010). According to Yordanova and Popova (2007), exposure of wheat plants to low temperature $\left(3^{\circ} \mathrm{C}\right)$ for 48 and $72 \mathrm{~h}$ resulted in decreased levels of chlorophyll, $\mathrm{CO}_{2}$ assimilation, transpirations rates and photosynthesis due to the reduced activities of ATP synthase, which further restricted RuBisCo regeneration and limited photophosphorylation (Allen and Ort, 2001). Physiobiochemical responses to cold stress in tetraploid and hexaploid wheat were studied where, the elevated levels of electrolyte leakage index, $\mathrm{H}_{2} \mathrm{O}_{2}$ and MDA content were observed in stressed plants (Nejadsadeghi et al., 2014).

According to some previous reports, oxidative stress as a result of chilling stress has been observed in some other crops also (Turan and Ekmekci, 2011). Cold stress adversely affected membrane properties and enzymatic activities leading to plant and tissue necrosis, as observed in banana (Musa spp.) (Chinnusamy et al., 2007). Some other crops, which are chilling-sensitive and have been studied for the adverse effects on growth and development include Coffee plant (Coffea Arabica; Alonso et al., 1997), tomato (Lycopersicum esculentum; Starck et al., 2000) and its wild varieties, potato (Solanum spp.; Svensson et al., 2002), Citrus plant (Hara et al., 2003), muskmelons (Cucumis melo; Wang et al., 2004), cotton (Gossipium hirusutum; Zhao et al., 2012), and sugarcane (Saccharum officinarum L; Badea and Basu, 2009; Thakur et al., 2010; Aghaee et al., 2011; Anjum et al., 2011; Zhu et al., 2013).

Some other crops, where damage due to ROS in response to heat stress has been reported are Gossipium hirsutum (CraftsBrandner and Law, 2000; Snider et al., 2009), Lycopersicon esculentum (Willits and Peet, 2001; Rivero et al., 2004; Wahid et al., 2007), Nicotiana tabacum (Wang et al., 2006; Tan et al., 2011), 
Malus domestica (Ma et al., 2008), Brassica juncea (Rani et al., 2013; Wilson et al., 2014), and Cucurbita sp. (Ara et al., 2013).

\section{REDOX HOMEOSTASIS IN TEMPERATURE-STRESSED CROPS HIGH TEMPERATURE STRESS}

Plants tend to combat ROS production by inducing an antioxidant system consisting of enzymatic and non-enzymatic components under extreme temperature conditions as their defense system and also maintain their redox homeostasis (Sairam and Tyagi, 2004; Wahid et al., 2007; Hasanuzzaman et al., 2013a) (Figure 5). Various studies on plants are available which indicate tolerance to temperature stress with an increase in antioxidants (Gill and Tuteja, 2010; Kaushal et al., 2011; Kumar et al., 2011, 2012b, 2013a; Hasanuzzaman et al., 2012a).

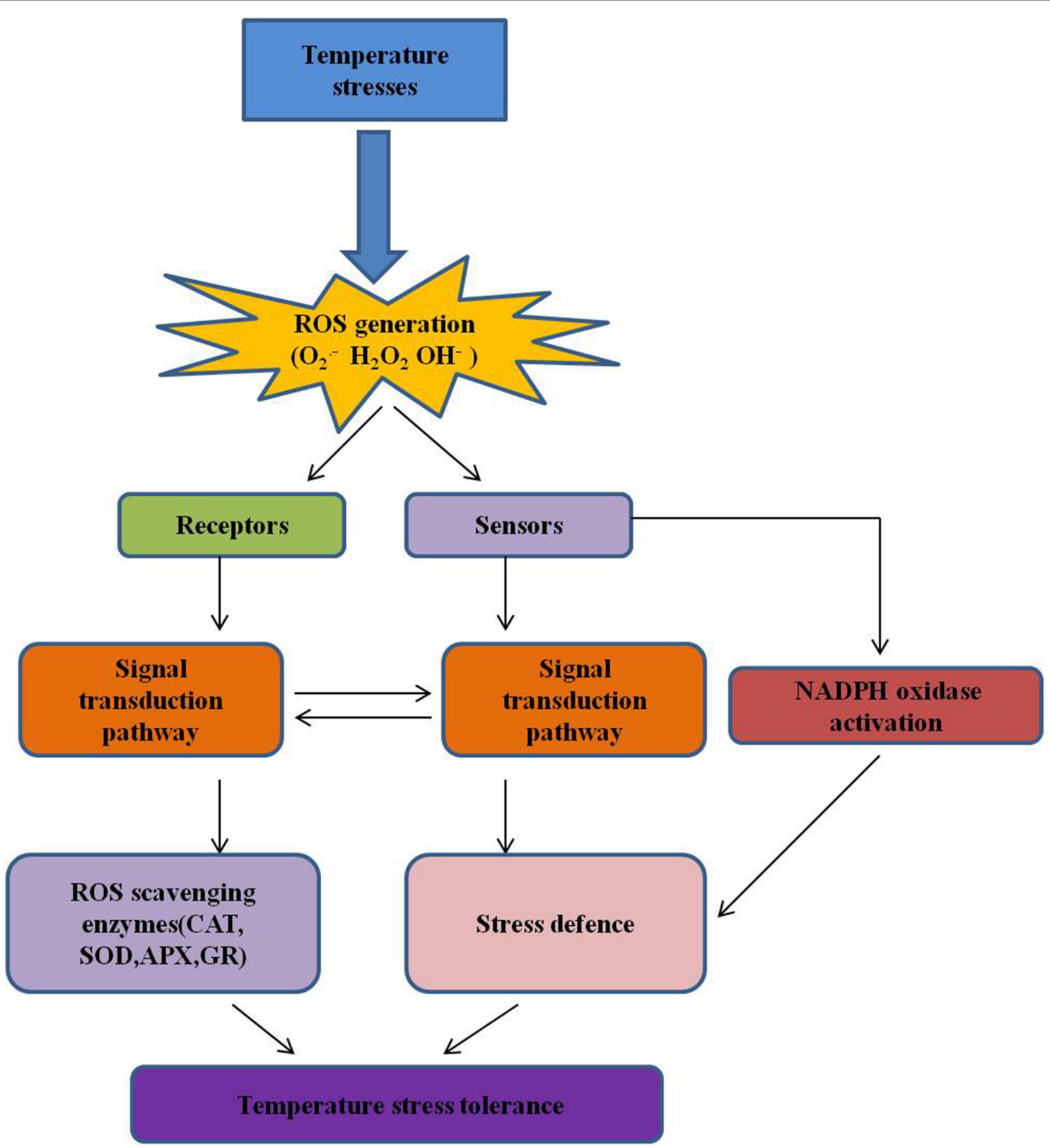

FIGURE 5 | ROS and redox homeostasis in temperature stress. ROS production in plant cells is a consequence of various stimuli due to abiotic stress, and modulation by antioxidants, as well as cell metabolism (Suzuki and Mittler, 2006). During stress, ROS overproduction can pose a threat to plant cells, and many stress conditions can enhance the expression of ROS-scavenging enzymes (De Gara et al., 2010). ROS are actively produced by cells (e.g., by NADPH oxidase in membranes) in stressful condition, and act as signals for the induction of defense pathways and eliciting specific cellular responses (Wahid et al., 2007). The influence of these molecules on cellular processes is mediated by both the perpetuation of their production and their scavenging by enzymes such as CAT, catalase; APX, ascorbate peroxidase; GPX guaiacol peroxidase; SOD, superoxide dismutase, and GR, glutathione reductase (Alscher et al., 2002; Suzuki et al., 2011). 
Though all the reports indicate to up-regulation of similar types of enzymatic and non-enzymatic antioxidants, their degree and type of expression varies depending upon the plant type, duration and intensity of the stress. Nagesh and Devaraj (2008) observed increased activities of glutathione reductase (GR), peroxidase (POX) and ascorbic acid content in Phaseolus vulgaris plants during high temperature stress. Increased levels of sugars, proline, glutathione and ascorbate and activities of peroxidase (POX), glutathione reductase (GR) and ascorbate peroxidase (APX) were observed in lablab (Dolichos lablab) seedlings (D'Souza and Devaraj, 2013). In lentil, Chakraborty and Pradhan (2011) observed initial increase in CAT, APX, and SOD activities as temperature increased from 20 to $50^{\circ} \mathrm{C}$ before declining at $50^{\circ} \mathrm{C}$. Likewise, in chickpea, the oxidative stress assessed by measuring the activity of enzymatic antioxidants such as CAT, SOD, APX, and GR elevated in plants grown at $40 / 35^{\circ} \mathrm{C}$ but decreased at $45 / 40^{\circ} \mathrm{C}$ (Kaushal et al., 2011). To cope up the oxidative stress, increased levels of antioxidants were observed at $40 / 30^{\circ} \mathrm{C}$, which decreased markedly at $45 / 35^{\circ} \mathrm{C}$ suggesting their impairment. Heat-tolerant genotypes possessed greater activities of ascorbate peroxidase (APX) and glutathione reductase (GR), which possibly influenced the heat tolerance (Kumar et al., 2011). Seedlings of soybean (Glycine max) exposed to high temperature at $45^{\circ} \mathrm{C}$ showed increased activities of peroxidases (POX), glutathione reductase (GR) and ascorbate peroxidase (APX) (D'Souza, 2013); similar findings have been observed in sorghum (Djanaguiraman et al., 2010). The activity of SOD, APX, CAT, GR, and POX increased significantly at all stages of growth in wheat cultivar C306 (heat-toelrant) while the PBW 343 (heat-sensitive) genotype showed a significant reduction in CAT, $\mathrm{GR}$, and POX activities in response to high temperature stress in wheat (Almeselmani et al., 2009). Thermotolerance acquired in a set of wheat (Triticum aestivum) genotypes was correlated with higher activities of antioxidants such as catalase and superoxide dismutase, higher ascorbic acid concentration and less oxidative damage (Sairam et al., 2000; Almeselmani et al., 2006). A study conducted on wheat by Baldawi et al. (2007) showed heat tolerance to be associated with higher activities of SOD, APX, GR, GST, and CAT. In an another study conducted by Kumar et al. (2012c), comparative responses of Oryza sativa and Zea mays revealed the higher expression of enzymatic and non-enzymatic antioxidants. In enzymatic oxidants CAT, APX, and GR were found to be significantly higher in Zea mays compared to Oryza sativa while no variations existed for superoxide dismutase at the highest temperature applied $\left(45 / 40^{\circ} \mathrm{C}\right)$, whereas the nonenzymatic antioxidants (AsA and GSH) were also maintained significantly at greater levels at $45 / 40^{\circ} \mathrm{C}$ in maize than in Oryza sativa genotypes. Therefore, Zea mays genotypes were able to retain their growth under heat stress partly due to their superior ability to cope up with oxidative damage by heat stress compared to Oryza sativa genotypes as suggested by these findings. The relative sensitivity of these plant groups to heat stress may also be reflected from the observation that Zea mays and Oryza sativa belong to $\mathrm{C}_{4}$ and $\mathrm{C}_{3}$ plant groups, respectively (Kumar et al., 2012c). Pearl millet plantlets showed significant increase in SOD, CAT and peroxidase activities during heat stress (Tikhomirova, 1985). In a similar fashion, exposure of a thermo-tolerant
(BPR5426) and thermo-sensitive (NPJ119) Indian mustard (Brassica juncea) genotype to high temperature $\left(45^{\circ} \mathrm{C}\right)$ revealed higher SOD, CAT, APX and GR activities in tolerant genotypes (Rani et al., 2013). Under heat stress conditions, activity of antioxidant enzymes such as SOD, APX, POX, CAT increased, while $\mathrm{H}_{2} \mathrm{O}_{2}$ and MDA decreased, which increased shoot weight in tomato (Ogweno et al., 2008). According to these various studies, maintaining the redox state is vital to tolerate mild heat stress while severe stress, even for short periods, impairs this ability. Therefore, understanding of the expression of antioxidants in heat-stressed plants of various crops may be a significant step toward improving redox state and heat tolerance in crop plants.

\section{LOW TEMPERATURE STRESS}

Low temperature stress was shown to enhance the transcript, protein, and activity of different ROS scavenging enzymes of antioxidative machinery which is linked to acquisition of stress tolerance (Saito et al., 2001; Posmyk et al., 2005; Morsy et al., 2007; Janska et al., 2009; Figure 5). Higher cold tolerance was observed in plants having enhanced activities of anti-oxidative enzymes in chickpea (Kumar et al., 2011). The chilling experiments carried out by Wang et al. (2009b) on alfalfa (Medicago sativa) genotypes with different chilling sensitivities showed that the chilling tolerant-genotypes had high anti-oxidative activity over the chilling-sensitive ones. The pod walls in chickpea exposed to cold stress upregulated the anti-oxidative enzymes to protect pods and developing seeds from chilling injury (Kaur et al., 2008). Cold acclimation in chickpea imparted cold tolerance at 2 and $4^{\circ} \mathrm{C}$, which was attributed to enhanced activities of SOD, APX, GR, and POX (Turan and Ekmekci, 2011). CAT, SOD and GR represent first lines of antioxidant defense which prevent formation of more toxic ROS and play essential role in cellular $\mathrm{H}_{2} \mathrm{O}_{2}$ signaling in chickpea (Shahandashti et al., 2014). In a subsequent study in chickpea, Turan and Ekmekci (2011) exposed the chickpea cultivars to chilling treatment and reported the enhanced activities of PSII and anti-oxidative enzymes in acclimated plants. Higher activities of CAT, APX and GR were found in pod walls of tolerant genotypes of chickpea which led to increased translocation of GSH from pod wall to seeds and contribute to ROS scavenging and tolerance to pod wall against low temperature stress (Kaur et al., 2009). Soybean seedlings exposed to very low temperature treatments $\left(1^{\circ} \mathrm{C}\right)$ resulted in increased activities of anti-oxidative enzymes (Posmyk et al., 2001, 2005; Borowski and Michalek, 2014). The tolerant genotypes of some cereals growing under cold stress showed higher expression of antioxidants implicating their role in governing the cold tolerance. In chillingtolerant winter rye leaves, the contents of ascorbic acid and $\alpha$-tocopherol were found to be increased appreciable than the sensitive genotype. Three antioxidant enzymes were studied in two wheat cultivars, winter wheat and spring wheat, under low temperature stress conditions. The levels of endogenous peroxides were strongly increased in spring cultivar and to lesser extent in winter wheat (Apostolova et al., 2008) at low temperature (Streb and Feierabend, 1999). In rice, higher activities of antioxidant enzymes (CAT, SOD, APX) and higher AsA content was recorded which possibly provided cold tolerance (Huang and Guo, 2005; Guo et al., 2006). Antioxidant enzymes have significant 
importance in providing chilling tolerance in cold-stressed Zea mays where levels of APX, MDHAR, DHAR, GR and SOD were found to be elevated (Hasanuzzaman et al., 2013a). There are some examples of other crops such as Coffea sp. (Hasanuzzaman et al., 2013a), tomato (Zhao et al., 2009), Cucumber (Yang et al., 2011), grapes (Wang and Li, 2006), Medicago sativa (Ibrahim and Bafeel, 2008) where cold tolerance has been reported to be linked to upregulation of various antioxidants.

\section{PLANT ACCLIMATION TO TEMPERATURE STRESSES AND REDOX HOMEOSTASIS HIGH TEMPERATURE STRESS}

Plants acclimate rapidly to different environmental conditions and manifest different mechanisms for surviving under extreme temperature conditions, together with long-term evolutionary adaptations at morphological and phonological level, involving changes in membrane lipid compositions, leaf orientation and transpirational cooling or short-term avoidance or acclimation mechanisms (Wahid et al., 2007; Larkindale and Vierling, 2008; Bita and Gerats, 2013). The acclimation of plants to moderately high temperature plays an important role in inducing plant tolerance to subsequent lethal high temperatures (He et al., 2003). Under high temperature conditions, many crop plants undergo early maturation, which is strongly related to decreased yield and may occur as a result of involvement of escape mechanism (Adams et al., 2001). Among general heat acclimation mechanisms involving various stress proteins, osmo-protectants, antioxidant enzymes, ion transporters and factors involved in signaling cascades and transcriptional control are essential to counteract stress effects (Wang et al., 2004; Bita and Gerats, 2013). During stress conditions, the initial stress signals arise in the form of osmotic or ionic effects or changes in temperature or membrane fluidity would trigger downstream signaling processes and transcription controls. This further activates various stress-responsive genes and mechanisms to re-establish homeostasis and protect and repair damaged proteins and membranes in plants during stressful conditions (Bohnert et al., 2006). Plants may experience high temperatures even in their natural distribution which would be lethal in the absence of this rapid acclimation response (Wahid et al., 2007). In addition, plants can experience major temperature fluctuations, leading to the acquisition of thermotolerance which may induce more general and variety of mechanisms that contribute to redox control of homeostasis of metabolism on a daily basis (Hong et al., 2003). During high temperature stress, the primary effects are on the plasmalemma, resulting in increased fluidity of lipid bilayer thereby leading to $\mathrm{Ca}^{2+}$ influx, cytoskeleton reorganization, which results in the up regulation of mitogen activated protein kinases (MAPK) and calcium dependent protein kinases (CDPK), heat shock element (HSE), heat shock proteins (HSPs) and histidine kinase (HSK) (Sung et al., 2003). These different signaling cascades lead to the production of antioxidants and compatible osmolytes for cell water balance and osmotic adjustment, which also maintain redox homeostasis in plant cells (Bohnert et al., 2006). Osmoprotectants accumulation is one of an important adaptive mechanism in plants subjected to extreme temperature conditions (Sakamoto et al., 2000). The accumulation of different osmoprotectants like proline, glycine betaine and soluble sugars is necessary to regulate osmotic activities and protect various cellular structures from temperature stresses by maintaining the cell-water balance, membrane stability and by buffering the cellular redox potential (Farooq et al., 2008). According to studies, higher availability of carbohydrates such as glucose and sucrose during heat stress represents an important physiological trait associated with stress tolerance and acclimation (Liu and Huang, 2000). Also, sugars have been shown to act as antioxidants in plants (Lang-Mladek et al., 2010). However, at lower concentrations, they act as signaling molecules, but at higher concentrations these act as ROS scavengers also (Sugio et al., 2009). For instance, in tomato, the high cell wall and vacuolar invertases activities and increased sucrose import into young fruit contribute to high temperature tolerance through increasing sink strength and sugar signaling activities ( $\mathrm{Li}$ et al., 2012). Furthermore, secondary metabolites like anthocyanins and carotenoids also help in plant acclimation responses by enhancing their synthesis and by decreasing leaf osmotic potential, resulting in an increased uptake and reduced transpirational loss of water under stress conditions (Wahid et al., 2007). Plants may accumulate phenolics by stimulation of their biosynthesis and inhibition of their catabolism as one of the acclimation mechanisms against temperature stress, as indicated by several studies in tomato and watermelon (Rivero et al., 2001; Wahid et al., 2007). The ability of plants to withstand or to acclimate to extreme temperature conditions results from repair of their heat-sensitive components and also the prevention of further heat injury and redox homeostasis being also maintained during stress (Kaya et al., 2001).

\section{LOW TEMPERATURE STRESS}

In cold acclimation, plants acquire stress tolerance on prior exposure to suboptimal, low and non-freezing temperatures however; various plant species differ in their ability to face cold stress, which is governed by appropriate changes in gene expression to alter their metabolism, physiology and growth (Chinnusamy et al., 2010). Plant species acclimate during cold stress, by synthesis of cryoprotective molecules such as soluble sugars (saccharose, raffinose, stachyose, trehalose), sugar alcohols (sorbitol, ribitol, inositol) and low-molecular weight nitrogenous compounds (proline, glycine betaine) (Janska et al., 2009). These molecules stabilize both membrane phospholipids and proteins, and cytoplasmic proteins in conjunction with dehydrin proteins (DHNs), cold-regulated proteins (CORs) and heat-shock proteins (HSPs). Cryoprotective solutes are also involved in maintenance of hydrophobic interactions, homeostasis of ions, protection of the plasma membrane from adhesion of ice, scavenging ROS and consequent damage to cells (Iba, 2002; Wang et al., 2003; Gusta et al., 2004, 2005; Chen and Murata, 2008; Janska et al., 2009).

Also, the increased activity of the antioxidative enzymes such as superoxide dismutase, glutathione peroxidase, glutathione reductase, ascorbate peroxidase and catalase, as well as the presence of a series of non-enzymatic antioxidants, such as tripeptidthiol, glutathione, ascorbic acid (vitamin C) and alphatocopherol (vitamin E) play important role in cold acclimation and maintanance of cellular redox homeostasis (Chen and $\mathrm{Li}$, 2002). Cold acclimation also affects cell lipid composition by 
increasing the proportion of unsaturated fatty acids making up the phospholipids, which is necessary for the maintenance of plasma membrane functionality (Rajashekar, 2000; De Palma et al., 2008). Cold-acclimation induced chilling tolerance in chickpea was found to be associated with marked increase in endogenous $\mathrm{ABA}$, cryoprotective solutes, antioxidative enzymes like ascorbate, glutathione, superoxide dismutase and catalase, relative growth rate of roots and significant decrease in electrolyte leakage and oxidative damage (Nayyar et al., 2005a). Some previous observations on this aspect also related higher chilling tolerance imparted by cold acclimation to elevated endogenous ABA (Janowiak et al., 2003), calcium (Knight et al., 1996), carbohydrates (Thomashow, 1999), and proline (Xin and Browse, 1998). During cold acclimation, changes in $\mathrm{H}_{2} \mathrm{O}_{2}$ concentrations and GSH/GSSG ratio alter the redox state of cells and activate special defense mechanisms through redox signaling chain (Kocsy et al., 2001). $\mathrm{H}_{2} \mathrm{O}_{2}$ generated by NADPH oxidase in the apoplast of plant cells plays a crucial role in cold acclimation induced chilling tolerance in tomato (Lycopersicon esculentum; Zhou et al., 2012). Some plants modulate their antifreeze activity by $\mathrm{Ca}^{2+}$, which is either released from pectin or bound to specific proteins and enhance the synthesis of proteins that inhibit the activity of ice nucleators in response to cold stress (Moffatt et al., 2006; Janska et al., 2009). An altered ratio of abscisic acid (ABA) to gibberellin content, in favor of $\mathrm{ABA}$, results in the retardation of growth required for cold acclimation (Juntilla et al., 2002). Gibberellin content is regulated by a family of nuclear growthrepressing proteins called DELLAs, and these are components of the C-repeat (CRT) binding factor 1 (CBF1)-mediated cold stress response. However, the degradation of DELLAs is stimulated by gibberellins (Achard et al., 2008). Various cellular changes induced by temperature stress and metabolic homeostasis are shown in model (Figure 6).

\section{STRATEGIES FOR THE DEVELOPMENT OF TEMPERATURE STRESS TOLERANCE INVOLVING REDOX HOMEOSTASIS EXOGENOUS MOLECULES IN REDOX HOMEOSTASIS IN PLANTS UNDER TEMPERATURE REGIMES}

Some molecules have the potential to protect the plants from the harmful and adverse effects of temperature stresses (Kaushal et al., 2011; Sharma et al., 2012) and these impart protection by managing the ROS. There are several reports where exogenous application of molecules such as proline (Pro), glycine betaine (GB), trehalose (Tre), brassiosteroids (Brs), polyamines (PAs), salicylic acid (SA), nitric oxide (NO), abscisic acid (ABA) and some trace elements like selenium etc. has shown beneficial effects on plant growth and development under stressful conditions by upregulation of antioxidant capacity (Tausz et al., 2004; Hefny and Abdel-Kader, 2009). Proline (Pro), a non-essential amino acid, is one of the most studied and extensively-reported thermoprotectant. Many studies have indicated a positive relationship between the accumulation of Pro and plant stress tolerance. Chickpea plants grown with exogenous Pro showed less injury to membranes, improved chlorophyll and water contents especially at $45 / 40^{\circ} \mathrm{C}$ due to protection of vital enzymes of antioxidant metabolism under heat stress (Kaushal et al., 2011). Proline, when exogenously applied to tobacco culture cells resulted in decreased lipid peroxidation but increased SOD and catalase activities (Islam et al., 2009). Supplementation with Pro and GB considerably reduced $\mathrm{H}_{2} \mathrm{O}_{2}$ production and showed decrease in oxidative injury coupled to elevated levels of antioxidants in sugarcane (Rasheed et al., 2011). According to Gao et al. (2013), under heat stress, pre-treatment with trehalose (Tre) protected proteins in the thylakoid membranes and the photosynthetic capacity, reduced electrolyte leakage, MDA content and hydrogen peroxide levels due to elevated levels of antioxidants. The potential of Tre to induce heat tolerance in other crops needs to be examined as has been reported for inducing cold tolerance. Likewise, induction of cold tolerance by glycine beatine was found to be associated with increase in leaf water content, chlorophyll and sucrose concentrations, reduction in ABA and oxidative damage (Nayyar et al., 2005d). When supplied with exogenous glycine betaine, cold-stressed cucumber plants showed better survival, enhanced photosynthetic efficiency, and reduced MDA content and ROS (Li et al., 2004). Similar cryoprotective effects of exogenously applied GB were also confirmed when applied to Medicago seedlings (Zhao et al., 1992), potato (Somersalo et al., 1996), strawberry (Rajashekar et al., 1999), maize (Farooq et al., 2008), and tomato (Park et al., 2006). Foliar application of GB has resulted in induction of tolerance against cold stress in Medicago sativa (Zhao et al., 1992), wheat (Allard et al., 1998), strawberry (Rajashekar et al., 1999), and chickpea (Nayyar et al., 2005d).

Abscisic acid (ABA) is a naturally-occurring compound that helps to regulate plant growth and development (Pospisilova et al., 2009). A significant increase in free and conjugated ABA was observed in tomato seedlings at $45 / 35^{\circ} \mathrm{C}$ compared to control plants $\left(25 / 15^{\circ} \mathrm{C}\right)$, which increased plant tolerance to temperature stress (Daie and Campbell, 1981). Likewise, ABA levels increased in response to heat treatment in tobacco (Teplova et al., 2000), which possibly is linked to redox homeostasis. There are reports where exogenous application of $10 \mu \mathrm{M}$ ABA alleviated heat stress symptoms by increasing SOD, CAT, APX, POX and decreasing $\mathrm{H}_{2} \mathrm{O}_{2}$ and MDA contents (Ding et al., 2010). In heat-stressed chickpea, exogenous application of $2.5 \mu \mathrm{M}$ ABA increased growth which was associated with enhanced endogenous ABA levels (Kumar et al., 2012b). Maize seedlings grown for 1-4 days in the presence of $\mathrm{ABA}$ were better able to withstand the effects of $3 \mathrm{~h}$ sub-lethal $\left(40^{\circ} \mathrm{C}\right)$ and lethal $\left(45^{\circ} \mathrm{C}\right)$ heat shocks to roots and shoots (Bonham-Smith et al., 1988). Pre-treatment of maize with $0.3 \mathrm{mML}^{-1} \mathrm{ABA}$ at $46^{\circ} \mathrm{C}$ improved the thermotolerance under heat stress (Gong et al., 1998). Heat tolerance increased significantly within $24 \mathrm{~h}$ of ABA application at 7.6 or $9.5 \mu \mathrm{M}$ in leaves and cell tissue culture in grapes (Abass and Rajshekhar, 1993). An ABA concentration of $10^{-5} \mathrm{M}$ inhibited heat-induced effects and enhanced thermostability of thylakoid organization in barley in response to heat stress (Ivanov et al., 1992). In cold-stressed plants too, ABA-treated plants showed significantly less oxidative damage, which was attributed to enhanced activities of various enzymatic and non-enzymatic antioxidants. The studies indicated that these plants showed improved cold tolerance as a result of increase in leaf water content and decrease in oxidative stress (Kumar et al., 2008).

Brassinosteroids (BRs) have a protective function under various abiotic stresses (Vardhini and Rao, 2003), which includes 


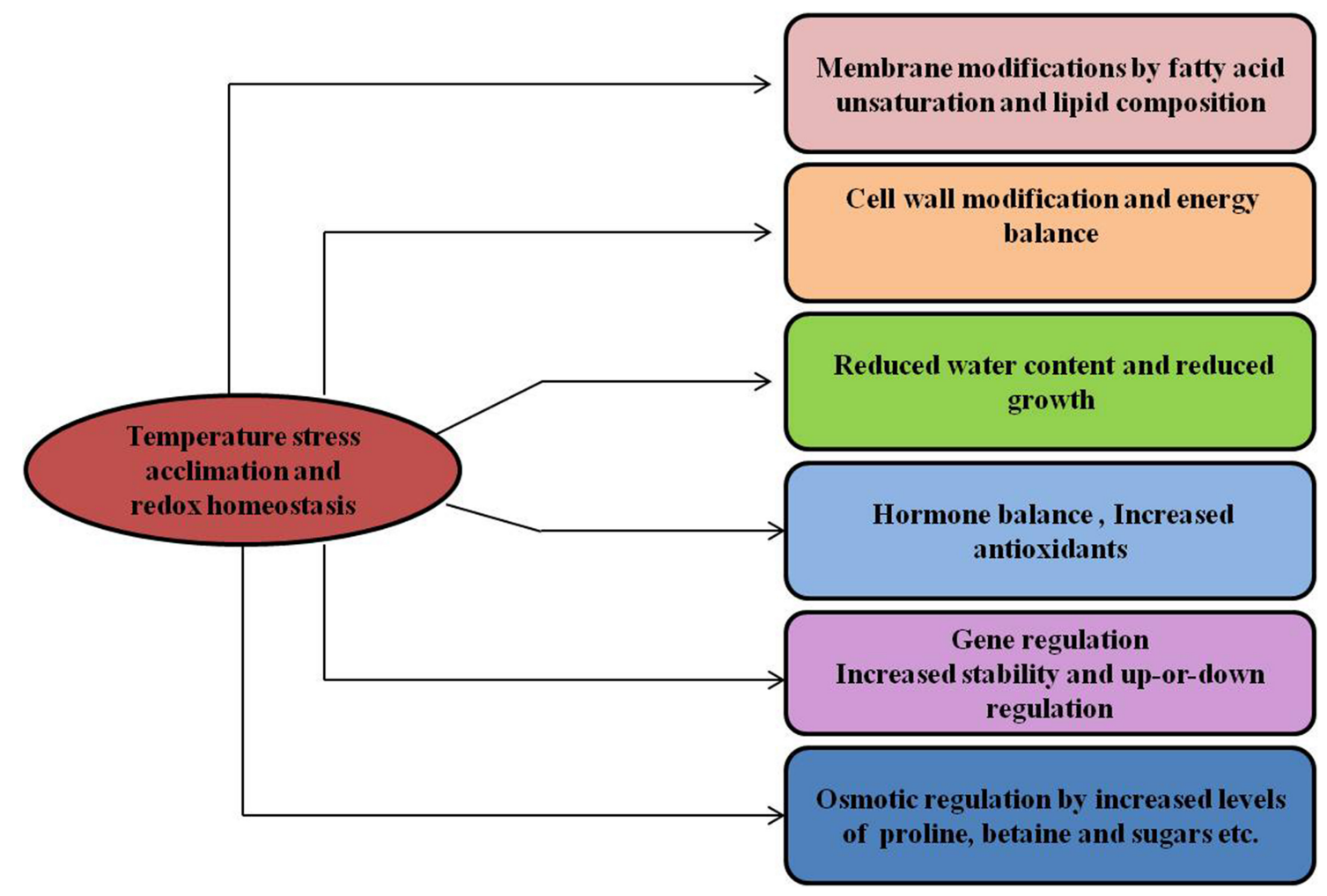

FIGURE 6 | Temperature stress and metabolic homeostasis. Temperature stress acclimation induces changes in many different cellular processes, provides stress tolerance and maintains the cellular redox state in plants.

enhancement of antioxidants. Exogenous application of BR has a promotory effect on the growth of wheat (Shahbaz et al., 2008), French bean (Upreti and Murti, 2004) and is involved in stimulating cell elongation under water stress conditions (Salchert et al., 1998). Supplementation with exogenous 24-BR's in tomato plants showed better responses under heat stress $\left(40 / 30^{\circ} \mathrm{C}\right)$. Activity of antioxidant enzymes such as SOD, APX, CAT were found to be increased, resulting in increase of shoot weight (Ogweno et al., 2008). A significant increase in net photosynthetic rate was reported by epibrassinosteroid (EBR) application to cucumber (Cucumis sativum L.; Yu et al., 2004) and tomato (Singh and Shono, 2005). The treatment of rapeseed and tomato seedlings with 24-epibrassinolide (a type of brassionosteroid) increased their basic thermotolerance (Dhaubhadel et al., 1999). In Indian mustard, application of different concentrations of 24epibrassinolide $\left(0,10^{-6}, 10^{-8}, 10^{-10} \mathrm{M}\right)$ on 10 -day-old seedlings at $40^{\circ} \mathrm{C}$ identified that $10^{-8} \mathrm{M}$ was most effective for temperature amelioration due to enhanced activity of antioxidant enzymes (SOD, CAT, APX; Kumar et al., 2012c). Exogenous application of BRs retarded the rate of chlorophyll degradation and proteins associated with these pigments particularly those associated with chloroplast thylakoid membranes (Hola, 2011). In cold-stressed plants too, BRs conferred protection by reducing the oxidative damage. Foliar application of 24-epibrassinolide reduced oxidative damage and accelerated recovery from photoinhibition of PSII by activation of enzymes in Calvin cycle and increased the antioxidant capacity in cucumber during cold stress $\left(10 / 7^{\circ} \mathrm{C}\right)$ (Jiang et al., 2013).

Salicylic acid is an important signaling molecule in plant defense responses (Yuan et al., 2008). Exogenous application of SA mitigates the effects of heat stress (Dat et al., 1998; Senaratna et al., 2003). In grape plants, exogenous pre-treatment with $0.1 \mathrm{mM}$ SA maintained relatively higher activities of POX, SOD, APX, GR, and MDHAR indicating that SA can induce intrinsic heat tolerance in grapevines (Wang and $\mathrm{Li}, 2006$ ). In another study on grapes treated with $100 \mu \mathrm{M} \mathrm{SA}$, exposure to $43^{\circ} \mathrm{C}$ resulted in higher RUBISCO activity, increased PSII function and hence photosynthesis (Wang et al., 2010). Likewise, $10^{-5} \mathrm{M}$ SA significantly increased all growth parameters, antioxidant activity and Pro levels in Indian mustard growing under heat stress $\left(30^{\circ} \mathrm{C}\right.$ and $40^{\circ} \mathrm{C}$ ) (Hayat et al., 2009). The results were confirmed by Kaur et al. (2009) who reported improved antioxidative abilities of CAT and POX in Brasscia species after exogenous application of 10 and $20 \mu \mathrm{M} \mathrm{SA}$ at high temperatures $\left(40-55^{\circ} \mathrm{C}\right)$. SA application enhanced SOD activity significantly at 2 and $12 \mathrm{~h}$ heat stress and increased CAT activity within $12 \mathrm{~h}$ ( $\mathrm{He}$ et al., 2003). In a study on six chickpea genotypes, seedlings were sprayed with $100 \mu \mathrm{M} \mathrm{L}^{-1} \mathrm{SA}$ at $46^{\circ} \mathrm{C}$ significantly reduced membrane injury, and enhanced protein and Pro contents which were accompanied by increased POX and APX activities (Chakraborty and Tongden, 2005). Pre-treatment of heat-stressed mungbean seedlings with SA reduced lipid peroxidation but improved 
membrane thermostability and antioxidant activity (Saleh, 2007). In cucumber, $1 \mathrm{mM}$ SA foliar spray reduced electrolyte leakage and $\mathrm{H}_{2} \mathrm{O}_{2}$ level, and increased catalase activity (Shi et al., 2006). SA application has been found to be effective for improving cold tolerance (Tuteja et al., 2013). For instance, SA can induce cold tolerance in barley (Hordeum vulgare) by regulating activities of apoplastic antioxidative enzymes (Mutlu et al., 2013).

Nitric oxide (NO) is considered a signaling molecule involved in the regulation of physiological processes and stress responses in plants (Hasanuzzaman et al., 2013b). NO is a highly reactive, membrane permeant free radical which plays a crucial role in many physiological processes such as seed germination, reduction of seed dormancy, leaf expansion, regulation of plant maturation and senescence (Mishina et al., 2007), suppression of floral transition (He et al., 2004), ethylene emission and stomatal closure (Garcia-Mata and Lamattina, 2002; Neill et al., 2002; Guo et al., 2003), programmed cell death and light-mediated greening (Zhang et al., 2006). Recently, it has attracted wide attention due to its protective role in stress responses in different plant species (Hasanuzzaman et al., 2013b). In wheat, application of 50 and $100 \mu \mathrm{M}$ SNP on two cultivars C306 (heat-tolerant) and PBW550 (heat-sensitive) growing at $33^{\circ} \mathrm{C}$ increased the activities of all antioxidant enzymes along with increased membrane thermostability and cellular viability (Bavita et al., 2012). In Mungbean, exogenous NO in the form of SNP during heat shock maintained the stability of chlorophyll a fluorescence, membrane integrity, $\mathrm{H}_{2} \mathrm{O}_{2}$ content and antioxidant enzyme activity (Yang et al., 2006). Similarly, exogenous application of 0.5 mM SNP on 8 -day-old heat-treated seedlings $\left(38^{\circ} \mathrm{C}\right)$ of wheat for 24 and $48 \mathrm{~h}$ significantly reduced the high-temperature-induced lipid peroxidation and $\mathrm{H}_{2} \mathrm{O}_{2}$ content but increased the chlorophyll content, ascorbic acid, reduced glutathione (GSH) and the oxidized glutathione (GSSG) ratio (Hasanuzzaman et al., 2012a,b). The protective effect was linked to up-regulation of the antioxidant and glyoxalase system (Hasanuzzaman et al., 2012a,b, 2013b). SNP pre-treatment reduced the heat-induced damage in rice seedlings (Uchida et al., 2002) and increased the survival rate of wheat leaves and maize seedlings (Lamattina et al., 2001) thus validating its role in thermotolerance.

Ascorbic acid (AsA) is the most abundant and low molecular weight potential antioxidant having key role in defense against oxidative stress caused by enhanced level of ROS (Horemans et al., 2000; Athar et al., 2008). It can directly quench superoxide $\left(\mathrm{O}_{2}^{-}\right)$, hydroxyl radicals $\left(\mathrm{OH}^{\cdot}\right)$, and singlet oxygen $\left({ }^{1} \mathrm{O}_{2}\right)$ thereby providing membrane protection and regenerating $\alpha$-tocopherols from tocopheroxyl radical, thereby, providing protection to membranes (Sharma et al., 2012). According to some reports, overexpression of enzymes involved in AsA biosynthesis confers temperature stress tolerance, as observed in some plants such as Lycopersicum esculentum, Solanum tuberosum (Chaves et al., 2002; Hemavathi et al., 2010; Radyuk et al., 2010), strawberry (Hemavathi et al., 2009). In Mungbean, plants treated with $50 \mu \mathrm{M}$ ascorbic acid exhibited significant enhancement in germination and growth of seedlings, pertinently under heat stress. AsAtreated plants showed less damage to membranes, cellular respiration, chlorophyll concentration and water status. Moreover, the oxidative stress was significantly reduced as a result of ASA application. Also, the increased activities of SOD, CAT and ascorbate peroxidase were found in AsA treated plants at 40/30 and 45/35 ${ }^{\circ} \mathrm{C}$ (Kumar et al., 2011).

Various signaling molecules providing stress tolerance are shown in Figure 7. Some other examples of crops with protective effects of exogenous molecules under stress conditions are shown in Table 1.

\section{TRANSGENICS}

Plants can sense, transduce and translate the signals associated with ROS into appropriate cellular response depending on cellular redox state (Bhattacharjee, 2005). ROS/redox signaling networks in chloroplast and mitrochondria have important roles in plant adaptations to stresses (Mittler, 2002; Hemantaranjan et al., 2014). These various signals help the plant in cellular homeostasis under stressful conditions by controlling essential processes like transcription, translation, energy metabolism and protein phosphorylation (Mittler et al., 2011; Bita and Gerats, 2013). Various molecular approaches are assisting to understand the concept of temperature stress tolerance in plants (Wang et al., 2003; Hemantaranjan et al., 2014). Plants tolerate stress by modulating multiple genes and by coordinating the expression of genes in different pathways (Vinocur and Altman, 2005; Hasanuzzaman et al., 2013b). The adverse effects of temperature stresses can be mitigated by developing crop plants with improved stress tolerance using various transgenic approaches (Rodriguez et al., 2005). Among different defensive mechanisms, expression of some special types of proteins called heat shock proteins (HSPs) appears to be universal in lower and higher organism (Wahid et al., 2007; Suzuki et al., 2011). Temperature stress-response signal transduction pathways and various defense mechanisms, involving heat shock transcription factors (HSFs) and heat shock proteins (HSPs) are thought to be intimately associated with ROS and help in defense mechanisms in plants by providing stress tolerance (Pnueli et al., 2003; Suzuki and Mittler, 2006; Zhang et al., 2008). According to various studies, an intimate relationship appears to exist between oxidative stress and heat shock response (Pucciariello et al., 2012). HSF's possibly act as direct sensors of ROS, as evidenced by earlier studies on mammals, Drosophila and yeast (Ritossa, 1962). HSP's act as molecular chaperones and stabilize several cellular proteins under temperature stress, which has been reported to be a highly conserved response (Ahn and Thiele, 2003; Suzuki and Mittler, 2006). ROS production leads to the transduction of signals and the expression of heat shock genes in tobacco (Konigshofer et al., 2008). Heat shock proteins (HSP) are present under normal conditions but their expression level increases when the cell is under stress or shock (Robert, 2003). In normal growth conditions, HSPs control cellular signaling, protein folding, translocation and degradation but under high temperature stress they prevent protein misfolding and aggregation, and also protect membranes in plants and maintain redox homeostasis (Bita and Gerats, 2013). These proteins function as molecular chaperones and play crucial role in protecting plants against stress and maintaining homeostasis in cell and helps in its survival during heat stress (Feder and Hofmann, 1999). In addition to the studies concerning expression of sHSPs/chaperones and manipulation of HSF gene expression, transgenic plants 


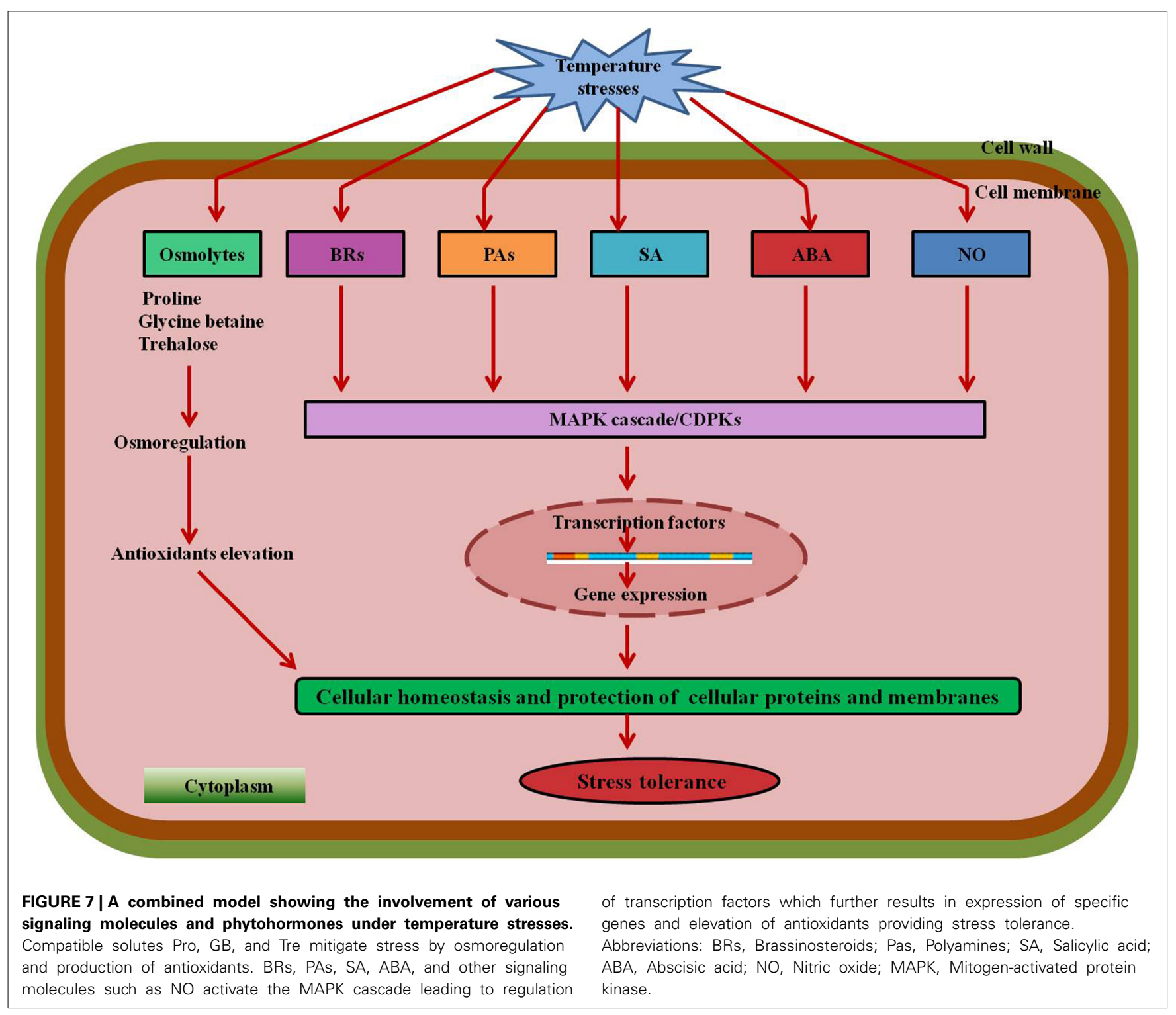

modified with other genes related to heat tolerance have been produced with varied success. Genetic improvement of proteins involved in osmotic adjustments, ROS detoxification, photosynthetic reactions and protein biosynthesis have showed positive results in developing transgenic plants with thermotolerance as shown in Table 2.

Diverse crop species tolerate low temperature to a varying degree, which depends on re-programming gene expression to modify their physiology, metabolism and growth (Sanghera et al., 2011). According to various studies, over-expression of combinations of antioxidant enzymes in transgenic plants has synergistic effect on stress tolerance (Kwon et al., 2003). Some of the stress-inducible genes especially encoding proteins which involve detoxification enzymes such as CAT, SOD, APX, GR etc. have been overexpressed in transgenic plants, further producing stress-tolerant phenotypes (Shinozaki et al., 2003). Simultaneous expression of multiple antioxidant enzymes, such as $\mathrm{Cu} / \mathrm{Zn}-\mathrm{SOD}$,
APX, and DHAR in chloroplast has shown to be more effective than single or double expression for developing transgenic plants with enhanced tolerance to multiple environmental stresses (Lee et al., 2007). Low temperature limitations have been overcome by the identification of cold- tolerant genes for transfer to genetically transformed crops. Therefore, transgenic plants overexpressing multiple antioxidants have increased emphasis in order to achieve cold tolerance (Sharma et al., 2012). Overexpresson of GR in Nicotiana tabacum and Populus plants leads to higher foliar AsA contents and improved tolerance to oxidative stress (Aono et al., 1993; Foyer et al., 1995) due to chilling injury. Tobacco plants genetically engineered to over-express chloroplast glycerol-3-phosphate acyltransferase (GPAT) gene (involved in phosphatidyl glycerol fatty acid desaturation), taken from Arabidopsis and Cucurbita maxima, were found to have enhanced cold tolerance, which was attributed to increase in number of unsaturated fatty acids. Higher lipid de-saturation of membranes 
Table 1 | Effects of some exogenous molecules involving antioxidants in various crops under temperature stress conditions.

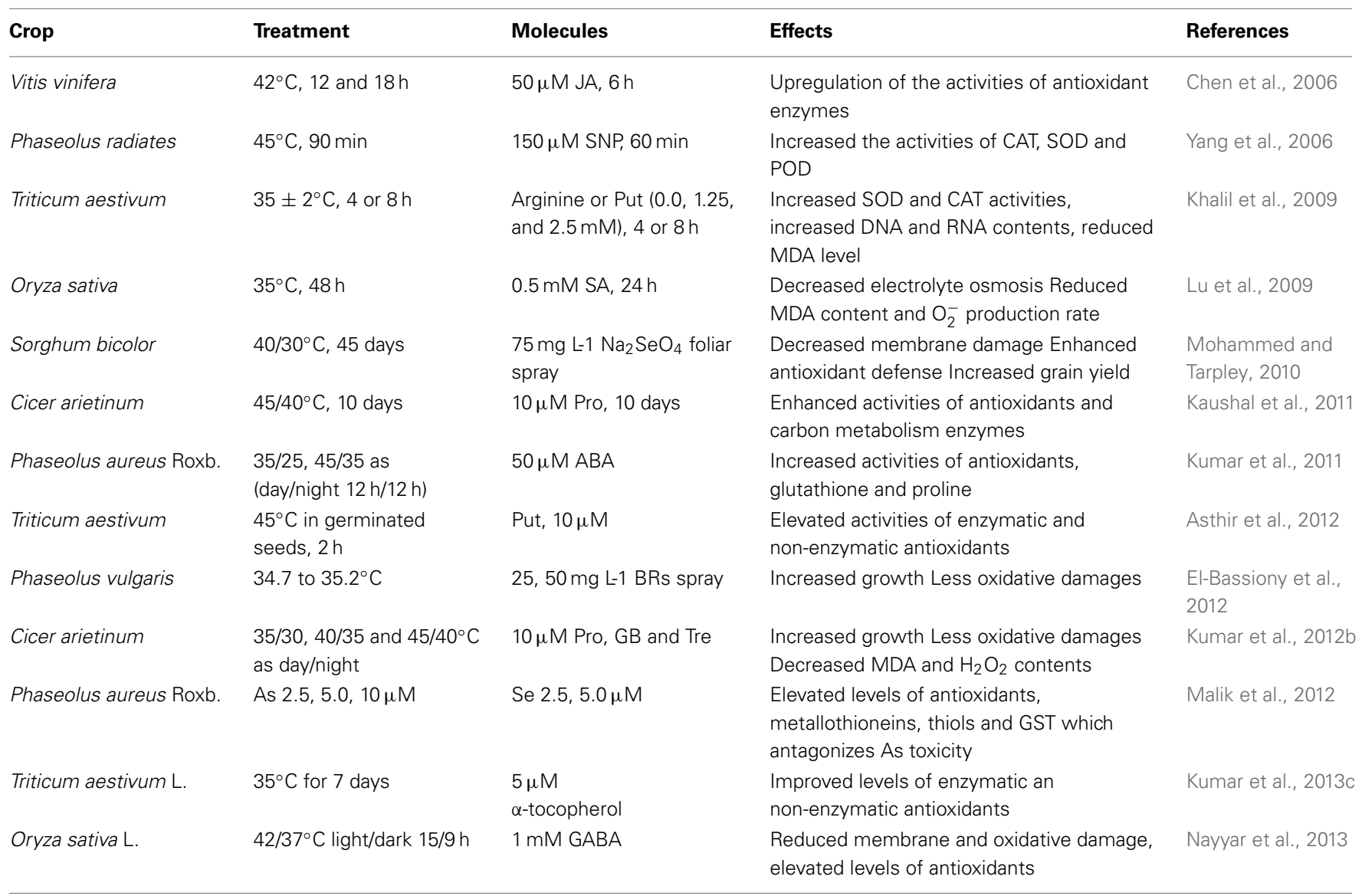

Table 2 | Transgenic plants having heat tolerance in various plant species and their responses to ROS scavenging.

\begin{tabular}{|c|c|c|c|c|}
\hline Transgene & Source & Transgenic plant & Functions & References \\
\hline$A N P 1 / N P K 1$ & N. tabacum & N. tabacum & $\begin{array}{l}\mathrm{H}_{2} \mathrm{O}_{2} \text { responsive MAPK kinase (MAPKKK) } \\
\text { production to protect against the } \\
\text { lethality in } \mathrm{HT}\end{array}$ & $\begin{array}{l}\text { Murakami et al., } \\
2000\end{array}$ \\
\hline Dnak1 & Aphanothece halophytica & N. tabacum & Thermotolerance & Ono et al., 2001 \\
\hline $\begin{array}{l}\text { APX1/HVAPX1(Ascorbate } \\
\text { peroxidase) }\end{array}$ & $\begin{array}{l}\text { P. sativum/ } \\
\text { H. vulgare }\end{array}$ & A. thaliana & $\begin{array}{l}\mathrm{H}_{2} \mathrm{O}_{2} \text { detoxification and conferred heat } \\
\text { tolerance }\end{array}$ & Shi et al., 2001 \\
\hline TLHS1 & N. tabacum & N. tabacum & Synthesis of sHSP and stress tolerance & Park and Hong, 2002 \\
\hline Hsp100, Hsp101 & A. thaliana & Z. mays, O. sativa & HSP synthesis for HT tolerance & $\begin{array}{l}\text { Katiyar-Agarwal } \\
\text { et al., } 2003\end{array}$ \\
\hline Hsp17.7 & D. carota & Daucus carota & $\begin{array}{l}\text { Synthesis of sHsp, } \\
\text { thermotolerance }\end{array}$ & $\begin{array}{l}\text { Murakami et al., } \\
2004\end{array}$ \\
\hline MT-sHSP & L. esculentum & N. tabacum & Molecular chaperone function in vitro & Sanmiya et al., 2004 \\
\hline $\begin{array}{l}B A D H \text { (betaine aldehyde } \\
\text { dehydrogenase) }\end{array}$ & Spinacia oleracea & N. tabacum & $\begin{array}{l}\text { Over-production of GB osmolyte that will } \\
\text { enhance the heat tolerance }\end{array}$ & Yang et al., 2005 \\
\hline Fad 7 & $\begin{array}{l}\text { N. tabacum } \\
\text { O. sativa }\end{array}$ & N. tabacum & $\begin{array}{l}\text { De-saturation of fatty acids that increased level } \\
\text { of unsaturated fatty acids and provide } \\
\text { HT tolerance }\end{array}$ & Sohn and Back, 2007 \\
\hline
\end{tabular}

is crucial for optimum membrane function in plants (Sanghera et al., 2011). In Nicotiana tabacum, chilling tolerance at $1^{\circ} \mathrm{C}$ for 7 days was achieved by over-expression of genes encoding chloroplast omega-3-fatty acid desaturase (Kodama et al., 1994). Transgenic rice seedlings overexpressing OsNAC5 (encodes for transcription factor to regulate stress response) or suppression 
of OsNAC5 expression by RNAi provided low temperature tolerance (Song et al., 2011). Also, the transgenic rice overexpressing Sod1 (encoding $\mathrm{Cu} / \mathrm{Zn}$ superoxide dismutase) were produced to obtain plants with improved tolerance to oxidative and cold stress (Cruz et al., 2013). Various crops have been genetically engineered to obtain plants with improved low temperature tolerance, which also involves reduction in oxidative stress (Table 3 ).

\section{CONCLUSION AND FUTURE PERSPECTIVES}

Extreme temperatures are considered as major abiotic stresses for crop plants and also they are the causes of consequences of present day climate change. Plants growing in temperature range exceeding their limits of adaptation have substantial influence on their metabolism, physiology and yield. A common response in the form of oxidative stress is often showed by plants exposed to extreme temperature conditions (Hasanuzzaman et al., 2013b). During temperature stresses, overproduction of ROS can be a major risk factor to plant cells and also enhance the expression of ROS detoxifying and scavenging enzymes (Hossain and Fujita, 2011). ROS scavenging enzymes or antioxidants form the network, having important roles in redox signaling in chloroplast and mitochondria. This redox signaling maintains a delicate balance of homeostasis between different cellular components and within each organelle (Suzuki and Mittler, 2006;
Suzuki et al., 2011). Under stress conditions, various important biological pathways such as regulation of gene expression, energy metabolism and protein phosphorylation are regulated by the cross-talk between different cellular components and redox signaling, further providing essential information on cellular redox state, associated with abiotic stress responses to optimize defense and survival (Foyer and Noctor, 2005, 2009). However, the extent of oxidative damage due to extreme temperature conditions depends largely on the duration of the adverse temperature, exposure of plant and their stage of growth. Therefore, there is need to develop the crop plants with temperature stress tolerance by exploring suitable and necessary strategies to manage oxidative stress. The use of the various exogenous molecules and the development of plants with different transgenes are important strategies to manage oxidative stress and maintain redox cellular state in plants. The ROS networks are interlinked with different networks in plants and control the temperature stress acclimation and tolerance. Various components involved in redox signaling networks may have individual signaling tasks within a given cellular compartment (Foyer and Noctor, 2003). Although in recent studies, the role of ROS and antioxidants in maintaining redox state has been intensively studied, but still there are open questions in this field. Therefore, it needs attention to study in detail the redox changes during cell growth, differentiation and division

Table 3 | Transgenics for cold tolerance and involvement of ROS scavenging mechanisms.

\begin{tabular}{|c|c|c|c|}
\hline Transgene & Host plant & Functions & References \\
\hline $\begin{array}{l}\text { Glycerol-3-phosphate acyltransferase } \\
\text { (gpat) }\end{array}$ & Nicotiana tabacum & Fatty acid unsaturation & Murata et al., 1992 \\
\hline Superoxide dismutase (SOD) & Nicotiana tabacum & Dismutation of toxic ROS intermediates & Gupta et al., 1993 \\
\hline $\begin{array}{l}\text { mn-SOD cDNA } \\
\text { (Mn-Superoxide dismutase) }\end{array}$ & Medicago sativa & $\begin{array}{l}\text { Dismutation of ROS intermediates in } \\
\text { mitrochondria, freezing tolerance }\end{array}$ & McKersie et al., 1996 \\
\hline $\begin{array}{l}\text { gst/gpx } \\
\text { (Glutathione-S-transferase/Gluthathione } \\
\text { peroxidase) }\end{array}$ & Nicitiana tabacum & $\begin{array}{l}\text { Detoxification of toxic substances and chilling } \\
\text { tolerance }\end{array}$ & Roxas et al., 1997 \\
\hline $\begin{array}{l}\text { WSC120/COR39 CCGAC sequences } \\
\text { like CRT/DREs in promoter }\end{array}$ & Triticum aestivum & Low temperature tolerance & Ouellet et al., 1998 \\
\hline $\begin{array}{l}\text { SCOF1 } \\
\text { (Cold inducible } \mathrm{Zn} \text { finger protein) }\end{array}$ & Glycine max & $\begin{array}{l}\text { Activate COR gene expression, increased } \\
\text { freezing tolerance }\end{array}$ & $\begin{array}{l}\text { Kim et al., 2001; } \\
\text { Kumar et al., 2012b, } \\
2013 a\end{array}$ \\
\hline CAT (Catalase) & $\begin{array}{l}\text { Oryza sativa L. Cv. Yuukara or } \\
\text { Matsumae }\end{array}$ & $\begin{array}{l}\text { Low temperature stress tolerance due to } \\
\text { effective detoxification of } \mathrm{H}_{2} \mathrm{O}_{2} \text { by CAT }\end{array}$ & $\begin{array}{l}\text { Matsumura et al., } \\
2002\end{array}$ \\
\hline $\begin{array}{l}\text { CuCOR19 } \\
\text { (Citrus dehydrin) }\end{array}$ & Nicotiana tabacum & $\begin{array}{l}\text { Inhibition of lipid peroxidation and increased } \\
\text { cold tolerance }\end{array}$ & Hara et al., 2003 \\
\hline GR (Glutathione reductase) & $\begin{array}{l}\text { Gossipium hirsutum L. } \\
\text { Cv.Coker } 312\end{array}$ & Chilling stress tolerance and photoprotection & Kornyeyev et al., 2003 \\
\hline DHAR (Dehydroascorbate reductase) & Nicotiana Tabacum cv.Xanthi & Detoxification of $\mathrm{H}_{2} \mathrm{O}_{2}$ & Kwon et al., 2003 \\
\hline Glutathione peroxidase (GPX) & Nicotiana Tabacum cv.Xanthi & $\begin{array}{l}\text { Chilling stress under high light intensity and } \\
\text { antioxidative defense }\end{array}$ & Yoshimura et al., 2004 \\
\hline HOS10 (Encodesan R2R3 type protein) & Oryza sativa & Chilling and freezing tolerance & Zhu et al., 2005 \\
\hline ScTPS1-ScTPS2 & Medicago sativa & Freezing tolerant & Saurez et al., 2009 \\
\hline DREB1C & Medicago truncatula & Freezing tolerance & Chen et al., 2010 \\
\hline CBF1CRT/DRE binding factor 1 & Solanum lycopersicum & $\begin{array}{l}\text { Higher SOD activity, lower MDA content and } \\
\text { cold tolerance }\end{array}$ & Zhang et al., 2010 \\
\hline MfGolS1 & Medicago falcata & $\begin{array}{l}\text { Raffinose accumulation } \\
\text { Cold tolerant }\end{array}$ & Zhao et al., 2012 \\
\hline
\end{tabular}


and also the specificity of the individual ROS and antioxidants and their interactions with hormone and secondary messengers during temperature-stress conditions. New insights into converging and diverging redox signaling pathways would be provided by the description of the redox-dependent spatial and temporal changes at various organization levels during plant growth and development and evaluation processes. Therefore, it could be useful for the better agriculture to clearly understand the redox control of plant growth, development and flowering. There are numerous research findings which support the notion that induction and regulation of antioxidant defenses are necessary for obtaining substantial tolerance against temperature stresses. Based on the various studies on redox environment, the modification of the cellular redox state may be used to increase the yield and stress tolerance in plants and to improve agriculture.

\section{REFERENCES}

Abass, M., and Rajshekhar, C. B. (1993). Abscisic acid accumulation in leaves and cultured cells during heat acclimation in grapes. Hortic. Sci. 28, 50-52.

Achard, P., Gong, F., Cheminant, S., Alioua, M., Hedden, P., and Genschik, P. (2008). The cold-inducible CBF1 factor-dependent signalling pathway modulates the accumulation of the growth- repressing DELLA proteins via its effect on gibberellin metabolism. Plant Cell 20, 2117-2129. doi: 10.1105/tpc.108. 058941

Adams, S., Cockshull, K., and Cave, C. (2001). Effect of temperature on the growth and development of tomato fruits. Ann. Bot. 88, 869-877. doi: 10.1006/anbo.2001.1524

Aghaee, A., Moradi, F., Maivan, H. Z., Zarinkamar, F., Irandoost, H. P., and Sharifi, P. (2011). Physiological responses of two rice (Oryza sativa L.) genotypes to chilling stress at seedling stage. Afr. J. Biotechnol. 10, 7617-7621. doi: 10.5897/AJB11.069

Ahmad, P., Umar, S., and Sharma, S. (2010). "Mechanism of free radical scavenging and role of phytohormones in plants under abiotic stresses," in Plant Adaptation and Phytoremediation, eds M. Ashraf, M. Ozturk, and M. S. A. Ahmad (Dordrecht; Heidelberg; London; New York, NY: Springer), 99-118.

Ahn, S. G., and Thiele, D. J. (2003). Redox regulation of mammalian heat shock factor 1 is essential for Hsp gene activation and protection from stress. Gene Dev. 17, 516-528. doi: 10.1101/gad.1044503

Allard, F., Houde, M., Krol, M., Ivanov, A., Huner, N. P. A., and Sarhan, F. (1998) Betaine improves freezing stolerance in wheat. Plant Cell Physiol. 39, 1194-1202. doi: 10.1093/oxfordjournals.pcp.a029320

Allen, D. J., and Ort, D. R. (2001). Impacts of chilling temperatures on photosynthesis in warm-climate plants. Trends Plant Sci. 6, 36-42. doi: 10.1016/S13601385(00)01808-2

Almeselmani, M., Deshmukh, P. S., and Sairam, R. K. (2009). High temperature stress tolerance in wheat genotypes: role of antioxidant defence enzymes. Acta. Agron. Hungar. 57, 1-14. doi: 10.1556/AAgr.57.2009.1.1

Almeselmani, M., Deshmukh, P. S., Sairam, R. K., Kushwaha, S. R., and Singh, T. P. (2006). Protective role of antioxidant enzymes under high temperature stress. Plant Sci. 171, 382-388. doi: 10.1016/j.plantsci.2006.04.009

Alonso, A., Queiroz, C. S., and Magalhaes, A. C. (1997). Chilling stress leads to increased cell membrane rigidity in roots of coffee (Coffea arabica L.) seedlings. Biochem. Biophys. Acta 1323, 75-84. doi: 10.1016/S0005-2736(96) 00177-0

Alscher, R. G., Erturk, N., and Heath, L. S. (2002). Role of superoxide dismutases (SODs) in controlling oxidative stress in plants. J. Exp. Bot. 53, 1331-1341. doi: 10.1093/jexbot/53.372.1331

Amirsadeghi, S., Robson, C. A., McDonald, A. E., and Vanlerberghe, G. C. (2006) Changes in plant mitochondrial electron transport alter cellular levels of reactive oxygen species and susceptibility to cell death signalling molecules. Plant Cell Physiol. 47, 1509-1519. doi: 10.1093/pcp/pcl016

Anjum, S. A., Yu Xie, X., Wang, L. C., Saleem, M. F., Man, C., and Lei, W. (2011). Morphological, physiological and biochemical responses of plants to drought stress. Afr. J. Agri. Res. 6, 2026-2032. doi: 10.5897/AJAR10.027
Aono, M., Kubo, A., Saji, H., Tanaka, K., and Kondo, N. (1993). Enhanced tolerance to photooxidative stress of transgenic Nicotiana tabacum with high chloroplastic glutathione reductase activity. Plant Cell Physiol. 34, 129-136.

Apel, K., and, Hirt, H. (2004). Reactive oxygen species: metabolism, oxidative stress, and signal transduction. Annu. Rev. Plant Biol. 55, 373-399. doi: 10.1146/annurev.arplant.55.031903.141701

Apostolova, P., Yordonova, R., and Popova, L. (2008). Response of antioxidative defence system to low temperature stress in two wheat cultivars. Gen. Appl. Physiol. 34, 281-294.

Ara, N., Yang, J., Zhongyuan, H. U., and Zhang, M. (2013). Determination of heat tolerance of interspecific (Cucurbita maxima x Cucurbita moschata) inbred line of squash 'maxchata' and its parents through photosynthetic response. J. Agri Sci. 19, 188-197.

Asada, K. (2006). Production and scavenging of reactive oxygen species in chloroplasts and their functions. Plant Physiol. 141, 391-396. doi: 10.1104/pp.106.082040

Asthir, B., Koundal, A., and Bains, N. S. (2012). Putrescine modulates antioxidant defense response in wheat under high temperature stress. Biol. Plant. 56, 757-761. doi: 10.1007/s10535-012-0209-1

Athar, H. R., Khan, A., and Ashraf, M. (2008). Exogenously applied ascorbic acid alleviates salt-induced oxidative stress in wheat. Environ. Exp. Bot. 63, 224-231. doi: 10.1016/j.envexpbot.2007.10.018

Badea, C., and Basu, S. K. (2009). The effect of low temperature on metabolism of membrane lipids in plants and associated gene expression. Plant Omics. 2, 78-84.

Bakht, J., Bano, A., and Dominy, P. (2006). The role of abscisic acid and low temperature in chickpea (Cicer arietinum) cold tolerance. II. Effects on plasmamembrane structure and function. J. Exp. Bot. 57, 707-715. doi: 10.1093/jxb/ erl120

Baldawi, M., Danyluk, J., Boucho, B., Houde, M., and Sarhan, F. (2007). The $\mathrm{CBF}$ gene family in hexaploid wheat and its relationship to the phylogenetic complexity of cereal CBFs. Mol. Genet. Genomics 277, 533-554. doi: 10.1007/s00438-006-0206-9

Barnabas, B., Jager, K., and Feher, A. (2008). The effect of drought and heat stress on reproductive processes in cereals. Plant Cell Environ. 31, 11-38. doi: 10.1111/j.1365-3040.2007.01727.x

Bavita, A., Shashi, B., and Navtej, S. B. (2012). Nitric oxide alleviates oxidative damage induced by high temperature stress in wheat. Indian J. Exp. Biol. 50, 372-378.

Beck, E. H., Fettig, S., Knake, C., Hartig, K., and Bhattarai, T. (2007). Specific and unspecific responses of plants to cold and drought stress. J. Bio. Sci. 32, 501-510. doi: 10.1007/s12038-007-0049-5

Berger, J. D., Ali, M., Basu, P. S., Chaudhary, B. D., Chaturvedi, S. K., Deshmukh, P. S., et al. (2006). Genotype by environment studies demonstrates the critical role of phenology in adaptation of chickpea (Cicer arietinum L.) to high and low yielding environments of India. Field Crop Res. 98, 230-244. doi: 10.1016/i.fcr.2006.02.007

Bethke, P. C., and Jones, R. L. (2001). Cell death of barley aleurone protoplasts is mediated by reactive oxygen species. Plant J. 25, 19-29. doi: 10.1111/j.1365313X.2001.00930.x

Bhattacharjee, S. (2005). Reactive oxygen species and oxidative burst: roles in stress, senescence and signal transduction in plants. Curr. Sci. 89, 1113-1121.

Bhattacharjee, S. (2012). The language of reactive oxygen species signalling in plants. J. Bot. 22:985298. doi: 10.1155/2012/985298

Bita, C. E., and Gerats, T. (2013). Plant tolerance to high temperature in a changing environment: scientific fundamentals and production of heat stress-tolerant crops. Front. Plant Sci. 4:273. doi: 10.3389/fpls.2013. 00273

Blokhnia, O., and Fagerstedt, K. V. (2006). "Oxidative stress and antioxidant defences in plants," in Oxidative Stress, Disease and Cancer, ed K. K. Singh (Helsinki: Imperial College Press), 151-199.

Blokhina, O., Virolainen, E., and Fagerstedt, K. V. (2003). Antioxidants, oxidative damage and oxygen deprivation stress: a review. Ann. Bot. 91, 179-194. doi: 10.1093/aob/mcf118

Board, J. E., and Kahlon, C. S. (2012). A proposed method for stress analysis and yield prediction in soybean using light interception and developmental timing. Crop Manage. 11:1 doi: 10.1094/CM-2012-0712-02-RS

Boguszewska, D., and Zagdanska, B. (2012). "ROS as signalling molecules and enzymes of plant response to unfavorable environmental conditions, oxidative 
stress-molecular mechanisms and biological effects," in Oxidative StressMolecular Mechanisms and Biological Effects, eds V. Lushchak and H. M. Semchyshyn (Croatia: InTech, JanezaTrdine), 341-362.

Bohnert, H. J., Gong, Q., Li, P., and Ma, S. (2006). Unravelling abiotic stress tolerance mechanisms-getting genomics going. Curr. Opin. Plant Biol. 9, 180-188. doi: $10.1016 /$ j.pbi.2006.01.003

Bonham-Smith, P. C., Kapoor, M., and Bewley, J. D. (1988). Exogenous application of abscisic acid or triadimefon affects the recovery of Zea mays seedlings from heat shock. Physiol. Plant 73, 27-30. doi: 10.1111/j.1399-3054.1988.tb09188.x

Borowski, E., and Michalek, S. (2014). The effect of chilling temperature on germination and early growth of domestic and Canadian soybean (Glycine max 1.) Merr.) cultivars. Acta Sci. Pol. Hortorum. Cultus 13, 31-43.

Chakraborty, U., and Pradhan, D. (2011). High temperature-induced oxidative stress in Lens culinaris, role of antioxidants and amelioration of stress by chemical pre-treatments. J. Plant Interact. 6, 43-52. doi: $10.1080 / 17429145.2010 .513484$

Chakraborty, U., and Tongden, C. (2005). Evaluation of heat accilimation and salicylic acid treatments as patent inducers of thermotolerance in Cicer arietinum L. Curr. Sci. 89, 382-389.

Chang, M. Y., Chen, S. L., Lee, C. F., and Chen, Y. M. (2001). Cold-acclimation and root temperature protection from chilling injury in chilling sensitive mungbean (Vigna radiata L.) seedlings. Bot. Bull. Acad. Sin. 42, 53-60.

Chaves, M. M., Pereira, J. S., Rodrigues, M. L., Ricardo, C. P. P., Osorio, M. L., Carvalho, I., et al. (2002). How plants cope with water stress in the field: photosynthesis and growth. Ann. Bot. 89, 907-916. doi: 10.1093/aob/mcf105

Chen, J., Wang, P., Mi, H. L., Chen, G. Y., and Xu, D. Q. (2010).Reversible association of ribulose-1, 5-bisphosphate carboxylase/oxygenase activase with the thylakoid membrane depends upon the ATP level and $\mathrm{pH}$ in rice without heat stress. J. Exp. Bot. 61, 2939-2950. doi: 10.1093/jxb/erq122

Chen, P., Yu, S., Zhan, Y., and Kang, X. L. (2006). Effects of jasmonate acid on thermotolerance of grape seedlings. J. Shihezi Univ. Nat. Sci. 24, 87-91.

Chen, T. H., and Murata, N. (2008). Glycinbetaine: an effective protectant against abiotic stress in plants. Trends Plant Sci. 13, 499-505. doi: 10.1016/j.tplants.2008.06.007

Chen, W. P., and Li, P. H. (2002). "Attenuation of reactive oxygen production during chilling in ABA-treated maize cultured cells," in Plant Cold Hardiness, eds C. Li and E. T. Palva (Dordrecht: Kluwer Academic Publishers), 223-233.

Chinnusamy, V., Zhu, J. K., and Sunkar, R. (2010). Gene regulation during cold stress acclimation in plants methods. Mol. Biol. 639, 39-55. doi: 10.1007/978-160761-702-0_3

Chinnusamy, V., Zhu, J., and Zhu, J. K. (2007). Cold stress regulation of gene expression in plants. Trends Plant Sci. 12, 10. doi: 10.1016/j.tplants.2007.07.00

Cossani, C. M., and Reynolds, M. P. (2012). Physiological traits for improving heat tolerance in wheat. Plant Physiol. 160, 1710-1718. doi: 10.1104/pp.112. 207753

Crafts-Brandner, S. J., and Law, R. D. (2000). Effect of heat stress on the inhibition and recovery of ribulose-1,5-bisphosphate carboxylase/oxygenase activation state. Planta 212, 67-74. doi: 10.1007/s004250000364

Croser, J. S., Clarke, H. J., Siddique, K. H. M., and Khan, T. N. (2003). Lowtemperature stress: implications for chickpea (Cicer arietinum L.) improvement. Crit. Rev. Plant Sci. 22, 185-219. doi: 10.1080/713610855

Cruz, R. P., Sperotto, R. A., Cargnelutti, D., Adamski, J. M., de Freitas, T. T., and Fett, J. P. (2013). Avoiding damage and achieving cold tolerance in rice plants. Food Energy Secur. 2, 96-119. doi: 10.1002/fes3.25

D'Souza, M., and Devaraj, V. R. (2013). Induction of thermotolerance through heat acclimation in lablab bean (Dolichos lablab). Afr. J. Biotechnol. 12, 5695-5704. doi: 10.5897/AJB2013.13074

D'Souza, M. R. (2013). Effect of traditional processing methods on nutritional quality of field bean. Adv. Biores. 4, 29-33.

Daie, J., and Campbell, W. F. (1981). Response of tomato plants to stressful temperatures increase in abscisic acid concentrations. Plant Physiol. 67, 26-29 doi: 10.1104/pp.67.1.26

Dat, J. F., Lopez-Delgado, H., Foyer, C. H, and Scott, I. M. (1998). Parallel changes in $\mathrm{H}_{2} \mathrm{O}_{2}$ and catalase during thermotolerance induced by salicylic acid or heat acclimation in mustard seedlings. Plant Physiol. 116, 1351-1357. doi: 10.1104/pp.116.4.1351

De Gara, L., Locato, V., Dipierro, S, and de Pinto, M. C. (2010). Redox homeostasis in plants: the challenge of living with endogenous oxygen production. Respir. Physiol. Neurobiol. 173, S13-S19. doi: 10.1016/j.resp.2010.02.007
Del Rio, L. A., Pasturi, G. M., Sandalio, J. M., and Hernadez, J. A. (2006). Reactive oxygen species and reactive nitrogen species in peroxisomes: production, scavenging and role in cell signalling. Plant Physiol. 141, 330-335. doi: 10.1104/pp.106.078204

De Palma, M., Grillo, S., Massarelli, I., Costa, A., Balogh, G., Vigh, L., et al. (2008). Regulation of desaturase gene expression, changes in membrane lipid composition and freezing tolerance in potato plants. Mol. Breeding 21, 15-26. doi: 10.1007/s11032-007-9105-y

Dhaubhadel, S., Chaudhary, S., Dobinson, K. F., and Krishna, P. (1999). Treatment with 24-epibrassinolide, a brassinosteroid, increases the basic thermotolerance of Brassica napus and tomato seedlings. Plant Mol. Biol. 40, 333-342. doi: 10.1023/A:1006283015582

Ding, W., Song, L., Wang, X., and Bi, Y. (2010). Effect of abscisic acid on heat stress tolerance in the calli from two ecotypes of Phragmites communis. Biol. Plant. 54, 607-613. doi: 10.1007/s10535-010-0110-3

Djanaguiraman, M., Prasad, P. V. V., and Al-Khatib, K. (2011). Ethylene perception inhibitor 1-MCP decreases oxidative damage of leaves through enhanced antioxidant defense mechanisms in soybean plants grown under high temperature stress. Env. Exp. Bot. 71, 215-223. doi: 10.1016/j.envexpbot.2010.12.006

Djanaguiraman, M., Prasad, P. V. V., and Seppanen, M. (2010). Selenium protects sorghum leaves from oxidative damage under high temperature stress by enhancing antioxidant defense system. Plant Physiol. Biochem. 48, 999-1007. doi: 10.1016/j.plaphy.2010.09.009

El-Bassiony, A. M., Ghoname, A. A., El-Awadi, M. E., Fawzy, Z. F., and Gruda, N. (2012). Ameliorative effects of brassinosteroids on growth and productivity of snap beans grown under high temperature. Gesunde Pflanzen. 64, 175-182. doi: 10.1007/s10343-012-0286-x

Farooq, M., Basra, S. M. A., Wahid, A., Cheema, Z. A., Cheema, M. A., and Khaliq A. (2008). Physiological role of exogenously applied glycine betaine in improving drought tolerance of fine grain aromatic rice (Oryza sativa L.). J. Agron. Crop Sci. 194, 325-333. doi: 10.1111/j.1439-037X.2008.00323.x

Farooq, M., Wahid, A., Ito, O., Lee, D. J., and Siddique, K. H. M. (2009). Advances in drought resistance of rice. Crit. Rev. Plant Sci. 28, 199-217. doi: $10.1080 / 07352680902952173$

Feder, M. E., and Hofmann, G. E. (1999). Heat-shock proteins, molecular chaperones, and the stress response: evolutionary and ecological physiology. Annu. Rev. Physiol. 61, 243-282. doi: 10.1146/annurev.physiol.61.1.243

Foyer, C. H., and Noctor, G. (2003). Redox sensing and signalling associated with reactive oxygen in chloroplasts, peroxisomes and mitochondria. Physiol. Plant 119, 355-364. doi: 10.1034/j.1399-3054.2003.00223.x

Foyer, C. H., and Noctor, G. (2005). Redox homeostasis and antioxidant signalling: a metabolic interface between stress perception and physiological responses. Plant Cell 177, 1866-1875. doi: 10.1105/tpc.105.033589

Foyer, C. H., and Noctor, G. (2009). Redox regulation in photosynthetic organisms: signalling, acclimation, and practical implications. Antioxid. Redox Signal. 11, 861-905. doi: 10.1089/ars.2008.2177

Foyer, C. H., and Noctor, G. (2012). Managing the cellular redox hub in photosynthetic organisms. Plant Cell Environ. 35, 199-201. doi: 10.1111/j.1365$3040.2011 .02453 \mathrm{x}$

Foyer, C. H., Souriau, N., Perret, S., Lelandais, M., Kunert, K. J., Pruvost, C., et al. (1995). Overexpression of glutathione reductase but not glutathione synthetase leads to increases in antioxidant capacity and resistance to photoinhibition in poplar trees. Plant Physiol.109, 1047-1057. doi: 10.1104/pp.109.3.1047

Gao, J., Wang, N., Xu, S. S., Li, Y., Wang, Y., and Wang, G. S. (2013). Exogenous application of trehalose induced $\mathrm{H}_{2} \mathrm{O}_{2}$ production and stomatal closure in Vicia faba. Biol. Plant. 57, 380-384. doi: 10.1007/s10535-012-0285-x

Garcia-Mata, C., and Lamattina, L. (2002). Nitric oxide and abscisic acid cross talk in guard cells. Plant Physiol. 128, 790-792. doi: 10.1104/pp.011020

Gechev, T. S., Van Breusegem, F., Stone, J. M., Denev, I., and Laloi, C. (2006). Reactive oxygen species as signals that modulate plant stress responses and programmed cell death. Bioessays 28, 1091-1101. doi: 10.1002/bies.20493

Gill, S. S., and Tuteja, N. (2010). Reactive oxygen species and antioxidant machinery in abiotic stress tolerance in crop plants. Plant Physiol. Biochem. 48, 909-930 doi: 10.1016/j.plaphy.2010.08.016

Gong, M., Li, Y. J., and Chen, S. Z. (1998). Abscisic acid-induced thermotolerance in maize seedlings is mediated by calcium and associated with antioxidant systems. J. Plant Physiol. 153, 488-496. doi: 10.1016/S0176-1617(98)80179-X

Gonzalez-Meler, M. A., Ribascarbo, M., Giles, L., and Siedow, J. N. (1999). The effect of growth and measurement temperature on the activity of the alternative 
respiratory pathway. Plant Physiol. 120, 765-772. doi: 10.1104/pp.120. 3.765

Guilioni, L, Wery, J., and Tardieu, F. (1997). Heat stress-induced abortion of buds and flowers in pea. Is sensitivity linked to organ age or to relations between reproductive organs? Ann. Bot. 80, 159-168. doi: 10.1006/anbo.1997.0425

Guo, F., Okamoto, M., and Crawford, N. M. (2003). Identification of a plant nitric oxide synthase gene involved in hormonal signalling. Sci. J. 302, 100-103. doi: $10.1126 /$ science. 1086770

Guo, Y. P., Zhou, H. F., and Zhang, L. C. (2006). Photosynthetic characteristics and protective mechanisms against photooxidation during high temperature stress in two citrus species. Sci. Hort. 108, 260-267. doi: 10.1016/j.scienta.2006.01.029

Gupta, A. S., Webb, R. P., Holaday, A. S., and Allen, R. D. (1993). Overexpression of superoxide dismutase protects plants from oxidative stress induction of ascorbate peroxidase in superoxide dismutase-overexpressing plants. Plant Physiol. 103, 1067-1073.

Gusta, L. V., Trischuk, R., and Weiser, C. J. (2005). Plant cold acclimation: the role of abscisic acid. J. Plant Growth Regul. 24, 308-318. doi: 10.1007/s00344-0050079-x

Gusta, L. V., Wisniewski, M., Nesbitt, N. T., and Gusta, L. L. (2004). The effect of water, sugars and proteins on the pattern of ice nucleation and propagation in acclimated and non-acclimated canola leaves. Plant Physiol. 135, 1642-1653. doi: $10.1104 /$ pp.103.028308

Hamada, A. M. (2001). Alteration in growth and some metabolic processes of broad bean plants during extreme temperatures exposure. Acta. Physiol. Plant 23, 193-200. doi: 10.1007/s11738-001-0008-y

Hara, M., Terashima, S., Fukaya, T., and Kubol, T. (2003). Enhancement of cold tolerance and inhibition of lipid peroxidation by citrus dehydrin in transgenic tobacco. Planta 217, 290-298.

Hasanuzzaman, M., Hossain, M. A., and Fujita, M. (2012b). Exogenous selenium pretreatment protects rapeseed seedlings from cadmium-induced oxidative stress by upregulating antioxidant defense and methylglyoxal detoxification systems. Biol. Trace Elem. Res. 149, 248-261. doi: 10.1007/s12011-012-9419-4

Hasanuzzaman, M., Hossain, M. A., Teixeira da Silva, J. A., and Fujita, M. (2012a). "Plant Responses and tolerance to abiotic oxidative stress: antioxidant defences is a key factors," in Crop Stress and Its Management: Perspectives and Strategies, eds V Bandi, A. K. Shanker, C. Shanker, and M. Mandapaka (Berlin: Springer), 261-316.

Hasanuzzaman, M., Nahar, K., Alam, M., Roychowdhury, R., and Fujita, M. (2013b). Physiological, biochemical, and molecular mechanisms of heat stress tolerance in plants. Int. J. Mol. Sci. 14, 9643-9684. doi: 10.3390/ijms140 59643

Hasanuzzaman, M., Nahar, K., and Fujita, M. (2013a). "Extreme temperatures, oxidative stress and antioxidant defense in plants," in Abiotic Stress-Plant Responses and Applications in Agriculture, eds K. Vahdati and C. Leslie (Rijeka: InTech), 169-205.

Hatfield, J. L., Boote, K. J., Kimball, B. A., Ziska, L. H., Izaurralde, R. C., Ort, D., et al. (2011). Climate impacts on agriculture: implications for crop production. Agron. J. 103, 351-370. doi: 10.2134/agronj2010.0303

Hayat, S., Masood, A., Yusuf, M., Fariduddin, Q., and Ahmad, A. (2009). Growth of Indian mustard (Brassica juncea L.) in response to salicylic acid under high-temperature stress. Braz. J. Plant Physiol. 21, 187-195. doi: 10.1590/S167704202009000300003

He, Y., Liu, Y., Cao, W., Huai, M., Xu, B., and Huang, B. (2003). Effects of salicylic acid on heat tolerance associated with antioxidant metabolism in Kentucky bluegrass. Crop Sci. 45, 988-995. doi: 10.2135/cropsci2003.0678

He, Y., Tang, R. H., Hao, Y., Stevans, R. D., Cook, C. W., Ahn, S. M., et al. (2004). Nitric oxide represses the Arabidopsis floral transition. Science 305, 1968-1971. doi: 10.1126/science. 1098837

Hefny, M., and Abdel-Kader, D. J. (2009). "Antioxidant-enzyme system as selection criteria for salt tolerance in forage sorghum genotypes (Sorghum bicolor $\mathrm{L}$. Moench)," in Salinity and Water Stress, eds M. Ashraf, M. Ozturk, and H. R. Athar (Dordrecht: Springer), 25-36.

Hemantaranjan, A., Bhanu, A. N., Singh, M. N., Yadav, D. K., Patel, P. K., Singh, R., et al. (2014). Heat stress responses and thermotolerance. Adv. Plants Agric. Res. 1:12. doi: 10.15406/apar.2014.01.00012

Hemavathi, C. P., Upadhyaya, C. P., Young, K. E., Akula, N., Soon Kim, H., Heung, J. J., et al. (2009). Over-expression of strawberry D-galacturonic acid reductase in potato leads to accumulation of vitamin $\mathrm{C}$ with enhanced abiotic stress tolerance. Plant Sci. 177, 659-667. doi: 10.1016/j.plantsci.2009.08.004
Hemavathi, C. P., Upadhyaya, K. E., Young, N., Akula, K. E., Young, S. C., Chun, D. H. K., et al. (2010). Enhanced ascorbic acid accumulation in transgenic potato confers tolerance to various abiotic stresses. Biotechnol. Lett. 32, 321-330. doi: 10.1007/s10529-009-0140-0

Hola, A. (2011). "Brassinosteroids and photosynthesis," in Brassinosteroids: A Class of Plant Hormone, eds S. Hayat and A. Ahmad (New York, NY: Springer), 143-192.

Hong, S. W., Lee, U., and Vierling, E. (2003). Arabidopsis hot mutants define multiple functions required for acclimation to high temperatures. Plant Physiol. 132, 757-767. doi: 10.1104/pp.102.017145

Horemans, N., Foyer, C. H., and Asard, H. (2000). Transport and action of ascorbate at the plant plasma membrane. Trends Plant Sci. 5, 263-267. doi: 10.1016/S1360-1385(00)01649-6

Hossain, M. A., and Fujita, M. (2011). "Regulatory role of components of ascorbate-glutathione (AsA-GSH) pathway in plant tolerance to oxidative stress," in Oxidative STRESS in Plants: Causes, Consequences and Tolerance, eds N. A. Anjum, S. Umar, and A. Ahmad (IK International Publishing House Pvt. Ltd.), 81-147. doi: 10.5772/22421

Hua, J. (2009). From freezing to scorching, transcriptional responses to temperature variations. Curr. Opin. Plant Biol. 12, 568-573. doi: 10.1016/j.pbi.2009. 07.012

Huang, M., and Guo, Z. (2005). Responses of antioxidant system to chilling stress in two rice cultivars differing in sensitivity. Biol. Plant. 49, 81-89. doi: $10.1007 / \mathrm{s} 00000-005-1084-3$

Iba, K. (2002). Acclimative response to temperature stress in higher plants: approaches of gene engineering for temperature tolerance. Annu. Rev. Plant Biol. 53, 225-245. doi: 10.1146/annurev.arplant.53.100201.160729

Ibrahim, H. M. (2011). Heat stress in food legumes: evaluation of membrane thermostability methodology and use of infra-red thermometry. Euphytica 180, 99-105. doi: 10.1007/s10681-011-0443-9

Ibrahim, M. M., and Bafeel, O. S. (2008). Photosynthetic efficiency and pigment contents in alfalfa (Medicago sativa) seedlings subjected to dark and chilling conditions. Int. J. Agric. Biol. 10, 306-310.

Ishikawa, H. A. (1996). Ultrastructural features of chilling injury: injured cells and the early events during chilling suspension-cultured mung bean cells. Am. J. Bot. 83, 825-835. doi: 10.2307/2446259

Islam, M. M., Hoque, M. A., Okuma, E., Banu, M. N. A., Shimoishi, Y., Nakamura, Y., et al. (2009). Proline and glycine betaine increase antioxidant enzyme activities and confer tolerance to cadmium stress in cultured tobacco cells. J. Plant Physiol. 166, 1587-1597. doi: 10.1016/j.jplph.2009.04.002

Ivanov, A. G., Kitcheva, M. I., Christov, A. M., and Popova, L. P. (1992). Effects of abscisic acid treatment on the thermostability of the photosynthetic apparatus in barley chloroplasts'. Plant Physiol. 98, 1228-1232. doi: 10.1104/pp.98. 4.1228

Janowiak, F., Luck, E., and Dorffling, K. (2003). Chilling tolerance of maize seedlings in the field during cold periods in spring is related to chillinginduced increase in abscisic acid level. J. Agron. Crop Sci. 189,156-161. doi: 10.1046/j.1439-037X.2003.00027.x

Janska, A., Mars, P., Zelenkova, S., and Ovesna, J. (2009). Cold stress and acclimation-what is important for metabolic adjustment? Plant Biol. 12, 395-405. doi: 10.1111/j.1438-8677.2009.00299.x

Jewell, M. C., Campbell, B. C., and Ian, D. (2010). "Transgenic plants for abiotic stress resistance," in Transgenic Crop Plants, eds C. Kole, C. Michler, A. G. Abott, and T. C. Hall (Berlin: Springer), 67-132.

Jiang, K., and Feldman, L. J. (2003). Root meristem establishment and maintenanace: the role of auxin. J. Plant Growth Regul. 21, 432-440. doi: 10.1007/s00344-002-0037-9

Jiang, Y. P., Huang, L. F., Cheng, F., Zhou, Y. H., Xia, X. J., Mao, W. H., et al. (2013). Brassinosteroids accelerate recovery of photosynthetic apparatus from cold stress by balancing the electron partitioning, carboxylation and redox homeostasis in cucumber. Physiol. Plant 148, 133-145. doi: 10.1111/j.13993054.2012.01696.x

Jung, H. L., Bae, Y. S., and Lee, J. S. (2001). Role of auxin-induced reactive oxygen species in root gravitropism. Plant Physiol. 126, 1055-1060. doi: 10.1104/pp.126.3.1055

Juntilla, O., Welling, A., Li, C., Berhany, A. T., and Palva, E. T. (2002). "Physiological aspects of cold hardiness in northern deciduous tree species," in Plant Cold Hardiness, eds C. H. Li and E. T. Palva (Dordrecht: Kluwer Academic Publishers), 65-76. 
Katiyar-Agarwal, S., Agarwal, M., and Grover, A. (2003). Heat tolerant basmati rice engineered by over-expression of hsp101. Plant Mol. Biol. 51, 677-686. doi: 10.1023/A:1022561926676

Kaur, G., Kumar, S., Nayyar, H., and Upadhyaya, H. D. (2008). Cold stress injury during the pod-filling phase inchickpea (Cicer arietinum L.). Effects on quantitative and qualitative components of seeds. J. Agron. Crop Sci. 194, 457-464. doi: 10.1111/j.1439-037X2008.00336x

Kaur, S., Gupta, A. K., Kaur, N., Sandhu, J. S., and Gupta, S. K. (2009). Antioxidative enzymes and sucrose synthase contribute to cold stress tolerance in chickpea. J. Agron. Crop Sci. 195, 393-397. doi: 10.1111/j.1439-037X.2009. 00383.x

Kaushal, N., Gupta, K., Bhandhari, K., Kumar, S., Thakur, P., and Nayyar, H. (2011). Proline induces heat tolerance in chickpea (Cicer arietinum L.) plants by protecting vital enzymes of carbon and antioxidative metabolism. Physiol. Mol. Biol. Plants 17, 203-213. doi: 10.1007/s12298-011-0078-2

Kaya, H., Shibahara, K., Taoka, K., Iwabuchi, M., Stillman, B., and Araki, T. (2001). FASCIATA- A genes for chromatin assembly factor-1 in Arabidopsis maintain the cellular organization of apical meristems. Cell 104, 131-142. doi: 10.1016/S0092-8674(01)00197-0

Khalil, S. I., El-Bassiouny, H. M. S., Hassanein, R. A., and Mostafa, H. A. (2009). Antioxidant defense system in heat shocked wheat plants previously treated with arginine or putrescine. Aust. J. Basic Appl. Sci. 3, 1517-1526.

Kim, H. S., Oh, J. M., Luan, S., Carlson, J. E., and Ahn, S. J. (2013). Cold stress causes rapid but differential changes in properties of plasma membrane $\mathrm{H}^{+}$-ATPase of camelina and rapeseed. J. Plant Physiol. 170, 828-837. doi: 10.1016/j.jplph.2013.01.007

Kim, S. Y., Hong, C. B., and Lee, I. (2001). Heat shock stress causes stagespecific male sterility in Arabidopsis thaliana. J. Plant Res. 114, 301-307. doi: 10.1007/PL00013991

Knight, H., Trewavas, A. J., and Knight, M. R. (1996). Cold calcium signalling in Arabidopsis involves two cellular pools and a change in calcium signature after acclimation. Plant Cell 8, 489-503. doi: 10.1105/tpc.8.3.489

Kocsy, G., Galiba, G., and Brunold, C. (2001). Role of glutathione in adaptation and signalling during chilling and cold acclimationin plants. Physiol. Planatarum. 113, 158-164. doi: 10.1034/j.1399-3054.2001.1130202.x

Kocsy, G., Tari, I., Vankova, R., Zechmanne, B., Gulyas, Z., Poor, P., et al. (2013). Redox control of plant growth and development. Plant Sci. 211, 77-91. doi: 10.1016/j.plantsci.2013.07.004

Kodama, H., Hamada, T., Horiguchi, G., Nishimura, M., and Iba, K. (1994). Genetic enhancement of cold tolerance by expression of a gene for chloroplast O-3 fatty acid desaturase in transgenic tobacco. Plant Physiol. 105, 601-605.

Konigshofer, H., Tromballa, H. W., and Loppert, H. G. (2008). Early events in signalling high-temperature stress in tobacco BY2 cells involve alterations in membrane fluidity and enhanced hydrogen peroxide production. Plant Cell Environ. 31, 771-1780. doi: 10.1111/j.1365-3040.2008.01880.x

Kornyeyev, D., Logan, B. A., Payton, P., Allen, R. D., and Holaday, A. S. (2003). Elevated chloroplastic glutathione reductase activities decrease chillinginduced photoinhibition by increasing rates of photochemistry, but not thermal energy dissipation, in transgenic cotton. Funct. Plant Biol. 30, 101-110. doi: 10.1071/FP02144

Kotak, S., Larkindale, J., Lee, U., von Koskull-Doring, P., Vierling, E., and Scharf, K. D. (2007). Complexity of the heat stress response in plants. Curr. Opin. Plant Biol. 10, 310-316. doi: 10.1016/j.pbi.2007.04.011

Kotchoni, S. O., and Gachomo, E. W. (2006). The reactive oxygen species network pathways: an essential prerequisite for perception of pathogen attack and the acquired disease resistance in plants. J. Biosci. 31, 389-404. doi: 10.1007/BF02704112

Kratsch, H. A., and Wise, R. R. (2000). The ultrastructure of chilling stress. Plant Cell. Environ. 23, 337-350. doi: 10.1046/j.1365-3040.2000.00560.x

Kreslavski, V. D., Los, D. A., Allakhverdiev, S. I., and Kuznetsov, V. V. (2012) Signalling role of reactive oxygen species in plants under stress. Russ. J. Plant Physiol. 59, 141-154. doi: 10.1134/S1021443712020057

Kumar, R. R., Goswami, S., Singh, K., Rai, G. K., and Rai, R. D. (2013b). Modulation of redox signal transduction in plant system through induction of free radical/ROS scavenging redox-sensitive enzymes and metabolites. Aus. J. Crop Sci. 7, 1744-1751.

Kumar, S., Gupta, D., and Nayyar, H. (2012c). Comparative response of maize and rice genotypes to heat stress: status of oxidative stress and antioxidants. Acta Physiol. Plantarum. 34, 75-86. doi: 10.1007/s11738-011-0806-9
Kumar, S., Kaur, G., and Nayyar, H. (2008). Exogenous application of abscisic acid improves coldtolerance in chickpea (Cicer arietinum L.). J. Agron. Crop Sci. 194, 449-456. doi: 10.1111/j.1439-037x.2008.00335x

Kumar, S., Kaur, R., Kaur, N., Bhandhari, K., Kaushal, N., Gupta, K., et al. (2011). Heat-stress induced inhibition in growth and chlorosis in mungbean (Phaseolusaureus Roxb.) is partly mitigated by ascorbic acid application and is related to reductionin oxidative stress. Acta Physiol. Plant 33, 2091-2101. doi: 10.1007/s11738-011-0748-2

Kumar, S., Kaushal, N., Nayyar, H., and Gaur, P. (2012b). Abscisic acid induces heat tolerance in chickpea (Cicer arietinum L.) seedlings by facilitated accumulation of osmoprotectants. Acta Physiol. Plant 34, 1651-1658. doi: 10.1007/s11738012-0959-1

Kumar, S., Kumari, P., Kumar, U., Grover, M., Singh, A. K., Singh, R., et al. (2012a). Molecular approaches for designing heat tolerant wheat. J. Plant Biochem. Biotechnol. 22, 359-371. doi: 10.1007/s13562-013-0229-3

Kumar, S., Singh, R., and Nayyar, H. (2013c). $\alpha$-Tocopherol application modulates the response of wheat (Triticum aestivum 1 .) seedlings to elevated temperatures by mitigation of stress injury and enhancement of antioxidants. J. Plant Growth Regul. 32, 307-314. doi: 10.1007/s00344-012-9299-z

Kumar, S., Thakur, P., Kaushal, N., Malik, J. A., Gaur, P., and Nayyar, H. (2013a). Effect of varying high temperatures during reproductive growth on reproductive function, oxidative stress and seed yield in chickpea genotypes differing in heat sensitivity. Arch. Agron. Soil Sci. 59, 823-843. doi: $10.1080 / 03650340.2012 .683424$

Kwon, S. Y., Choi, S. M., Ahn, Y. O., Lee, H. S., Lee, H. B., Park, Y. M., et al. (2003). Enhanced stress-tolerance of transgenic tobacco plants expressing a human DHAR gene. J. Plant Physiol. 160, 347-353. doi: 10.1078/0176-1617-00926

Lamattina, L., Beligni, M. V., Garcia-Mata, C., and Laxalt, A. M. (2001). Method of Enhancing the Metabolic Function and the Growing Conditions of Plants and Seeds. US Patent. US 6242384 B1.

Lang, P., Zhang, C. K., Ebel, R. C., Dane, F., and Dozier, W. A. (2005). Identification of cold acclimated genes in leaves of Citrus unshiu by mRNA differential display. Gene 359, 111-118. doi: 10.1016/j.gene.2005.06.013

Lang-Mladek, C., Popova, O., Kiok, K., Berlinger, M., Rakic, B., Auf-satz, W., et al. (2010). Transgenerational inheritance and resetting of stress-induced loss of epigenetic gene silencing in Arabidopsis. Mol. Plant. 3, 594-602. doi: $10.1093 / \mathrm{mp} / \mathrm{ssq} 014$

Larkindale, J., and Huang, B. (2004). Thermotolerance and antioxidant systems in Agrostis stoloifera: involvement of salicylic acid, abscisic acid, cadmium, hydrogen peroxide and ethylene. J. Plant Physiol. 161, 405-413. doi: 10.1078/01761617-01239

Larkindale, J., and Vierling, E. (2008). Core genome responses involved in acclimation to high temperature. Plant Physiol. 146, 2748-2761.

Laskowski, M. J., Dreher, K. A., Gehring, M. A., Abel, S., Gensler, A. L., and Sussex, I. M. (2002). FQR1, a novel primary auxin-response gene, encodes a flavin mononucleotide-binding quinone reductase. Plant Physiol. 128, 578-590. doi: 10.1104/pp.010581

Lawlor, D. W., and Cornic, G. (2002). Photosynthetic carbon assimilation and associated metabolism in relation to water deficits in higher plants. Plant Cell Environ. 25, 275-294. doi: 10.1046/j.0016-8025.2001.00814.x

Lee, S. H., Ahsan, N., Lee, K. W., Kim, D. H., Lee, D. G., and Kwak, S. S. (2007). Simultaneous overexpression of both $\mathrm{Cu}-\mathrm{Zn}$ superoxide dismutase and ascorbate peroxidase in transgenic tall fescue plants confers increased tolerance to a wide range of abiotic stresses. J. Plant Physiol. 164, 1626-1638. doi: 10.1016/j.jplph.2007.01.003

Li, M., Ji, L., Yang, X., Meng, Q., and Guo, S. (2012). The protective mechanisms of CaHSP26 in transgenic tobacco to alleviate photoinhibition of PSII during chilling stress. Plant Cell Rep. 31, 1969-1979. doi: 10.1007/s00299-012-1309-x

Li, Y. Y., Liang, G. J., and Li, Y. H. (2004). Effect of exogenous betaine on cold resistance of cucumber seedlings. Plant Physiol. Commun. 40, 673-676.

Lin, C. Y., Roberts, J. K., and Key, J. I. (1984). Acquisition of thermotolerance in Soybean seedlings' synthesis and accumulation of heat shock proteins and their cellular localization. Plant Physiol. 74, 152-160. doi: 10.1104/pp.74.1.152

Liu, X., and Huang, B. (2000). Carbohydrate accumulation in relation to heat stress tolerance in two creeping bent grass cultivars. J. Am. Soc. Hortic. Sci. 125, 442-447.

Lu, J., Zhang, R., Zong, X. F., Wang, S. G., and He, G. H. (2009). Effect of salicylic acid on heat resistance of rice seedling under heat stress. Chin. J. Eco-Agric. 17, 1168-1171. doi: 10.3724/SP.J.1011.2009.01168 
Ma, Y. H., Ma, F. W., Zhang, J. K, Li, M. J., Wang, Y. H, and Liang, D. (2008). Effects of high temperature on activities and gene expression of enzymes involved in ascorbate-glutathione cycle in apple leaves. Plant Sci. 175,761-766. doi: 10.1016/j.plantsci.2008.07.010

Malik, J. A., Goel, S., Kaur, N., Sharma, S., Singh, I., and Nayyar, H. (2012). Selinium antagonises the toxic effects of arsenic on mungbean (Phaseolus vulgaris Roxb.) plants by restricting its uptake and enhancing the antioxidative and detoxification mechanisms. Environ. Exp. Bot. 77, 242-248. doi: 10.1016/j.envexpbot.2011.12.001

Mansoor, S., and Naqvi, F. N. (2013). Effect of heat stress on lipid peroxidation and antioxidant enzymes in mung bean (Vigna radiata L.) seedlings. Afr. J. Biotechnol. 12, 3196-3203. doi: 10.5897/AJB12.2808

Matsumura, T., Tabayashi, N., Kamagata, Y., Souma, C., and Saruyama, H. (2002). Wheat catalase expressed in transgenic rice can improve tolerance against low temperature stress. Physiol. Plant 116, 317-327. doi: 10.1034/j.13993054.2002.1160306.x

McDonald, G. K., and Paulsen, G. M. (1997). High temperature effects on photosynthesis and water relations of grain legumes. Plant Soil. 196, 47-58. doi: 10.1023/A:1004249200050

McKersie, B. D., Bowley, S. R., Harjanto, E., and Leprince, O. (1996). Water deficit tolerance and field performance of transgenic alfalfa overexpressing superoxide dismutase. Plant Physiol. 111, 1177-1181.

Mhamdi, A., Queval, G., Chaouch, S., Vanderauwera, S., Breusegem, F. V., and Noctor, G. (2010). Catalase function in plants: a focus on Arabidopsis mutants as stress-mimic models. J. Exp. Bot. 61, 4197-4220. doi: 10.1093/jxb/erq282

Miller, G., Shulaevb, V., and Mittlera, R. (2008). Reactive oxygen signalling and abiotic stress. Physiol. Plantarum. 133, 481-489. doi: 10.1111/j.13993054.2008.01090.x

Mishina, T. E., Lamb, C., and Zeier, J. (2007). Expression of a nitric oxide degrading enzyme induces a senescence programme in Arabidopsis. Plant Cell Environ. 30, 39-52. doi: 10.1111/j.1365-3040.2006.01604.x

Mishkind, M., Vermeer, J. E., Darwish, E., and Munnik, T. (2009). Heat stress activates phospholipase $\mathrm{D}$ and triggers PIP2 accumulation at the plasma membrane and nucleus. Plant J. 60, 10-21. doi: 10.1111/j.1365-313X.2009.03933.x

Mittler, R. (2002). Oxidative stress, antioxidants and stress tolerance. Trends Plant Sci. 7, 405-410. doi: 10.1016/S1360-1385(02)02312-9

Mittler, R. (2006). Abiotic stress, the field environment and stress combination. Trends Plant Sci. 11, 15-19. doi: 10.1016/j.tplants.2005.11.002

Mittler, R., Vanderauwera, S., Gollery, M., and Van Breusegem, F. V. (2004). Reactive oxygen gene network of plants. Trends Plant Sci. 9, 490-498. doi: 10.1016/j.tplants.2004.08.009

Mittler, R., Vanderauwera, S., Suzuki, N., Miller, G., Tognetti, V. B., Vandepoele, K., et al. (2011). ROS signalling: the new wave? Trends Plant Sci. 16, 300-309. doi: 10.1016/j.tplants.2011.03.007

Miura, K., and Furumoto, T. (2013). Cold signalling and cold response in plants. Int. J. Mol. Sci. 14, 5312-5337. doi: 10.3390/ijms14035312

Moffatt, B., Ewart, V., and Eastman, A. (2006). Cold comfort: plant antifreeze proteins. Physiol. Plantarum. 126, 5-16. doi: 10.1111/j.1399-3054.2006. 00618.x

Mohammed, A. R., and Tarpley, L. (2010). Effects of high night temperature and spikelet position on yield-related parameters of rice (Oryza sativa L.) plants. Eur. J. Agron. 33, 117-123. doi: 10.1016/j.eja.2009.11.006

Morsy, M. R., Jouve, L., Hausman, J. F., Hoffmann, L., and Stewart, J. (2007). Alteration of oxidative and carbohydrate metabolism under abiotic stress in two rice (Oryza sativa L.) genotypes contrasting in chilling tolerance. J. Plant Physiol. 164, 157-167. doi: 10.1016/j.jplph.2005.12.004

Munro, K. D., Hodges, D. M., DeLong, J. M., Forney, C. F., and Kristie, D. N. (2004). Low temperature effects on ubiquinone content, respiration rates and lipid peroxidation levels of etiolated seedlings of two differentially chilling-sensitive species. Physiol. Plantarum. 121, 488-497. doi: 10.1111/j.13993054.2004.00352.x

Murakami, T., Matsuba, S., Funatsuki, H., Kawaguchi, K., Saruyama, H., Tanida, M., et al. (2004). Overexpression of a small heat shock protein, sHSP17.7, confers both heat tolerance and UV-B resistance to rice plants. Mol. Breed. 13, 165-175. doi: 10.1023/B:MOLB.0000018764. 30795.c1

Murakami, Y., Matsufuji, S., Hayashi, S., Tanahashi, N., and Tanaka, K. (2000). Degradation of ornithine decarboxylase by the 26S proteasome. Biochem. Biophys. Res. Commun. 267, 1-6. doi: 10.1006/bbrc.1999.1706
Murata, N., Ishizaki-Nishizawa, O., Higashi, S., Hayashi, H., Tasaka, Y., and Nishida, I. (1992). Genetically engineered alteration in the chilling sensitivity of plants. Nature 356, 710-713. doi: 10.1038/356710a0

Mutlu, O., Karadagoglu, O., Atici, O., and Nalbantoglu, B. (2013). Protective role of salicylic acid applied before cold stress on antioxidative system and protein patterns in barley apoplast. Biol. Plantarum. 57, 507-513. doi: 10.1007/s10535013-0322-4

Nagesh, B. R., and Devaraj, V. R. (2008). High temperature and salt stress response in French bean (Phaseolus vulgaris). Aus. J. Crop Sci. 2, 40-48.

Nayyar, H., Bains, T. S., and Kumar, S. (2005a). Chilling stressed chickpea seedlings: effect of cold acclimation, calcium and abscisic acid on cryoprotective solutes and oxidative damage. Environ. Exp. Bot. 54, 275-285. doi: 10.1016/j.envexpbot.2004.09.007

Nayyar, H., Bains, T. S., and Kumar, S. (2005b). Low temperature induced floral abortion in chickpea: relationship to abscisic acid and cryoprotectants in reproductive organs. Environ. Exp. Bot. 53, 39-47. doi: 10.1016/j.envexpbot.2004.02.011

Nayyar, H., Bains, T. S., Kumar, S., and Kaur, G. (2005c). Chilling effects during seed filling on accumulation of seed reserves and yield of chickpea. J. Sci. Food Agric. 85, 1925-1930. doi: 10.1002/jsfa.2198

Nayyar, H., Chander, K., Kumar, S., and Bains, T. (2005d). Glycine betaine mitigates cold stress damage in Chickpea. Agron. Sustain. Dev. 25, 381-388. doi: 10.1051/agro:2005033

Nayyar, H., and Chander, S. (2004). Protective effects of polyamines against oxidative stress induced by water and cold stress in chickpea. J. Agron. Crop Sci. 190, 355-365, 710-713. doi: 10.1111/j.1439-037X.2004.00106.x

Nayyar, H., Kaur, R., Kaur, S., and Singh, R. (2013). $\gamma$-Aminobutyric Acid (GABA) Imparts Partial Protection from Heat Stress Injury to Rice Seedlings by Improving Leaf Turgor and Upregulating Osmoprotectants and Antioxidants. J. Plant Growth Regul. 33, 408-419. doi: 10.1007/s00344-013-9389-6

Neill, S., Barros, R., Bright, J., Desikan, R., Hancock, J., Harrison, J., et al. (2008). Nitric oxide, stomatal closure, and abiotic stress. J. Exp. Bot. 5, 165-176. doi: 10.1093/jxb/erm293

Neill, S., Desikan, R., and Hancock, J. (2002). Hydrogen peroxide signalling. Curr. Opin. Plant Biol. 5, 388-395. doi: 10.1016/S1369-5266(02)00282-0

Nejadsadeghi, L., Maali-Amiri, R., Zeinali, H., Ramezanpour, S., and Sadeghzade, B. (2014). Comparative analysis of physio-biochemical responses to cold stress in tetraploid and hexaploid wheat. Cell Biochem. Biophys. 70, 399-408. doi: 10.1007/s12013-014-9925-4

Noctor, G., De Paepe, R., and Foyer, C. H. (2007). Mitochondrial redox biology and homeostasis in plants. Trends Plant Sci. 12, 125-134. doi: 10.1016/j.tplants.2007.01.005

Noctor, G., and Foyer, C. H. (1998). Ascorbate and glutathione: keeping active oxygen under control. Ann. Rev. Plant Physiol. Plant Mol. Biol. 49, 249-279. doi: 10.1146/annurev.arplant.49.1.249

Ogweno, J. O., Song, X. S., Shi, K., Hu, W. H., and Mao, W. H., Zhou. et al. (2008). Brassinosteroids alleviate heat-induced inhibition of photosynthesis by increasing carboxylation efficiency and enhancing antioxidant systems in Lycopersicon esculentum. J. Plant Growth Regul. 27, 49-57. doi: 10.1007/s00344-0079030-7

Ohnishi, S., Miyoshi, T., and Shirai, S. (2010). Low temperature stress at different flower developmental stages affects pollen development, pollination, and pod set in soybean. Environ. Exp. Bot. 69, 56-62. doi: 10.1016/j.envexpbot.2010.02.007

Ono, E., Wong, H. L., Kawasaki, T., Hasegawa, M., Kodama, O., and Shimamoto, K. (2001). Essential role of the small GTPase Rac in disease resistance of rice. Proc. Natl. Acad. Sci. U.S.A. 98, 759-764. doi: 10.1073/pnas.98.2.759

Ouellet, F. (2007). Cold Acclimation and Freezing Tolerance in Plants. (London: Encyclopedia of Life Sciences, John Wiley \& Sons, Ltd.), 1-6.

Ouellet, F., Vazquez-Tello, A., and Sarhan, F. (1998). The wheat wcs120 pro- moter is cold-inducible in both monocotyledonous and dicotyle- donous species. FEBS Lett. 423, 324-328. doi: 10.1016/S0014-5793(98)00116-1

Park, E. J., Jeknic, Z., Tony, H., and Chen, H. (2006). Exogenous application of glycine betaine increases chilling tolerance in tomato plants. Plant Cell Physiol. 47, 706-714. doi: 10.1093/pcp/pcj041

Park, S. M., and Hong, C. B. (2002). Class I small heat shock protein gives thermotolerance in tobacco. J. Plant Physiol. 159, 25-30. doi: 10.1078/0176-1617-00660

Pnueli, L., Liang, H., Rozenberg, M., and Mittler, R. (2003). Growth suppression, altered stomatal responses, and augmented induction of heat shock proteins in 
cytosolic ascorbate peroxidase (Apx1)-deficient Arabidopsis plants. Plant J. 34, 187-203. doi: 10.1046/j.1365-313X.2003.01715.x

Posmyk, M. M., Bailly, C., Szafranska, K., Jana, K. M., and Corbineau, F. (2005). Antioxidant enzymes and isoflavonoids in chilled soybean (Glycine max (L.) Merr.) seedling. J. Plant Physiol. 162, 403-412. doi: 10.1016/j.jplph.2004.08.004

Posmyk, M. M., Corbineau, F., Vinel, D., Bailly, C., and Come, D. (2001). Osmoconditioning reduces physiological and biochemical damage induced by chilling in soybean seeds. Physiol. Plant 111, 473-482. doi: 10.1034/j.13993054.2001.1110407.x

Pospisilova, J., Synkova, H., Haisel, D., and Batkova, P. (2009). Effect of abscisic acid on photosynthetic parameters during ex vitro transfer of micro-propagated tobacco plantlets. Biol. Plant 53, 11-20. doi: 10.1007/s10535-009-0003-5

Pucciariello, C., Banti, V., and Perata, P. (2012). ROS signalling as common element in low oxygen and heat stresses. Plant Physiol. Biochem. 59, 3-10. doi: 10.1016/j.plaphy.2012.02.016

Radyuk, M. S., Domanskaya, I. N., Shcherbakov, R. A., and Shalygo, N. V. (2010). Effect of low above zero temperature on the content of low molecular antioxidants and activities of antioxidant enzymes in green barley leaves. Russ. J. Plant Physiol. 56, 175-180. doi: 10.1134/S1021443709020058

Rajashekar, C. B. (2000). "Cold response and freezing tolerance in plants," in Plant Environ. Interactions, 2nd Edn., ed R. E. Wilkinson (New York, NY: Marcel Dekker, Inc.), 321-341.

Rajashekar, C. B., Zhou, H., Marcum, K. B., and Prakash, O. (1999). Glycine betaine accumulation and induction of cold tolerance in strawberry (Fragaria $\times$ ananassa Duch.) plants. Plant Sci. 148, 175-183. doi: 10.1016/S01689452(99)00136-3

Rani, T., Yadav, R. C., Yadav, N. R., Rani, A., and Singh, D. (2013). A genetic transformation in oilseed brassicas-a review. Indian J. Agri. Sci. 83, 367-373.

Rasheed, R., Wahid, A., Farooq, M., Hussain, I., and Basra, S. M. A. (2011). Role of proline and glycinebetaine pretreatments in improving heat tolerance of sprouting sugarcane (Saccharum sp.) buds. Plant Growth Regul. 65, 35-45. doi: 10.1007/s10725-011-9572-3

Reddy, S., Bhatnagar-Mathur, P., Vadez, V., and Sharma, K. K. (2012). "Grain legumes (Soybean, Chickpea, and Peanut): omics approaches to enhance abiotic stress tolerance," in Improving Crop Resistance to Abiotic Stress, 1st Edn., eds N. Tuteja, S. S. Gill, A. F. Tiburcio, and R. Tuteja (Wiley-VCH Verlag GmbH \& Co. KGaA), 993-1030.

Ritossa, F. (1962). A new puffing pattern induced by temperature shock and DNP in Drosophila. Experientia 18, 571-573. doi: 10.1007/BF02172188

Rivero, R. M., Ruiz, J. M., Garcia, P. C., Lopez-Lefebre, L. R., Sanchez, E., and Romero, L. (2001). Resistance to cold and heat stress: accumulation of phenolic compounds in tomato and watermelon plants. Plant Sci. 160, 315-321. doi: 10.1016/S0168-9452(00)00395-2

Rivero, R. M., Ruiz, J. M., and Romero, L. (2004). Iron metabolism in tomato and water-melon plants: influence of grafting. J. Plant Nutri. 27, 2221-2234. doi: 10.1081/PLN-200034708

Robert, J. (2003). Evolution of heat shock protein and immunity. Dev. Comp. Immunol. 27, 449-464. doi: 10.1016/S0145-305X(02)00160-X

Rodriguez, M., Canales, E., and Hidalgo, O. B. (2005). Molecular aspects of abiotic stress in plants. Biotecnol. Aplicada. 22, 1-10.

Roxas, V. P., Smith, R. K. Jr., Allen, E. R., and Allen, R. D. (1997). Overexpression of glutathione S-transferase/glutathione peroxidase enhances the growth of transgenic tobacco seedlings during stress. Nat. Biotechnol. 15, 988-991. doi: 10.1038/nbt1097-988

Saidi, Y., Finka, A., and Goloubinoff, P. (2011). Heat perception and signalling in plants: a tortuous path to thermotolerance. New Phytol. 190, 556-565. doi: 10.1111/j.1469-8137.2010.03571.x

Saidi, Y., Finka, A., Muriset, M., Bromberg, Z., Weiss, Y. G., Maathuis, F. J., et al. (2009). The heat shock response in moss plants is regulated by specific calciumpermeable channels in the plasma membrane. Plant Cell 21, 2829-2843. doi: $10.1105 /$ tpc. 108.065318

Sairam, R. K., and Tyagi. (2004). A Physiology and molecular biology of salinity stress tolerance in plants. Curr. Sci. 86, 407-421.

Sairam, R. K., Srivastava, G. C., and Saxena, D. C. (2000). Increased antioxidant activity under elevated temperatures: a mechanism of heat stress tolerance in wheat genotypes. Biol. Planatarum. 43, 245-251. doi: 10.1023/A:1002756311146

Saito, K., Miura, K., Nagano, K., Hayano-Saito, Y., Araki, H., and Kato, A. (2001). Identification of two closely linked quantitative trait loci for cold tolerance on chromosome 4 of rice and their association with anther length. Theor. Appl. Genet. 103, 862-868. doi: 10.1007/s001220100661

Sakamoto, A., Valverde, R., Alia., Chen, T. H., and Murata, N. (2000). Transformation of Arabidopsis with the $\operatorname{codA}$ gene for choline oxidase enhances freezing tolerance of plants. Plant J. 22, 449-453. doi: 10.1046/j.1365313X.2000.00749.x

Salchert, K., Bhalerao, R., Koncz-Kalman, Z., and Koncz, C. (1998). Control of cell elongation and stress responses by steroid hormones and carbon catabolic repression in plants. Philos. Trans. R. Soc. London Ser. 353, 1517-1520. doi: 10.1098/rstb.1998.0307

Saleh, A. H. (2007). Amelioration of chilling injuries in mung bean (Vigna radiate L.) seedlings by paclobutrazol, abscisic acid and hydrogen peroxide. Am. J. Plant Physiol. 2, 318-332. doi: 10.3923/ajpp.2007.318.332

Sandhu, J. S., Gupta, S. K., Singh, S., and Dua, R. P. (2007). Genetic variability for cold tolerance in pigeonpea. J. Sat. Agri. Res. 5, 1-3.

Sanghera, G. S., Wani, S. H., Hussain, W., and Singh, N. B. (2011). Engineering cold stress tolerance in crop plants. Curr. Genomics 12, 30-43. doi: $10.2174 / 138920211794520178$

Sanmiya, K., Suzuki, K., Egawa, Y., and Shono, M. (2004). Mitochondrial small heat shock protein enhances thermotolerance in tobacco plants. FEBS Lett. 557, 265-268. doi: 10.1016/S0014-5793(03)01494-7

Saurez, R., Calderon, C., and Iturriaga, G. (2009). Enhanced tolerance to multiple abiotic stresses in transgenic alfalfa accumulating trehalose. Crop Sci. 49, 1791-1799. doi: 10.2135/cropsci2008.09.0573

Savicka, M., and Skute, N. (2010). Effects of high temperature on malondialdehyde content, superoxide production and growth changes in wheat seedlings (Triticum aestivum L.). Ekologija 56, 26-33. doi: 10.2478/v10055-010-0004-x

Senaratna, T., Merrit, D., Dixon, K., Bunn, E., Touchell, D., and Sivasithamparam, K. (2003). Benzoic acid may act as the functional group in salicylic acid and derivatives in the induction of multiple stress tolerance in plants. Plant Growth Regul. 39, 77-81. doi: 10.1023/A:1021865029762

Shahandashti, S. S. K., Maali-Amiri, R., Zeinali, H., and Ramezanpour, S. S. (2014). Change in membrane fatty acid compositions and cold-induced responses in chickpea. Mol. Biol. Rep. 40, 893-903. doi: 10.1007/s11033-012$2130-\mathrm{x}$

Shahbaz, M., Ashraf, M., and Athar, H. U. R. (2008). Does exogenous application of 24-epibrassinolide ameliorate salt induced growth inhibition in wheat (Triticum aestivum L.)? Plant Growth Regul. 55, 51-64. doi: 10.1007/s10725-0089262-y

Sharkey, T. D. (2005). Effects of moderate heat stress on photosynthesis: importance of thylakoid reactions, rubisco deactivation, reactive oxygen species, and thermotolerance provided by isoprene.Plant Cell Environ. 28, 269-277. doi: 10.1111/j.1365-3040.2005.01324.x

Sharma, P., Jha, A. B., Dubey, R. S., and Pessarakli, M. (2012). Reactive oxygen species, oxidative damage and antioxidative defence mechanisms in plants under stressful conditions. J. Bot. 2012, 1-26. doi: 10.1155/2012/217037

Shi, Q., Bao, Z., Zhu, Z., Ying, Q., and Qian, Q. (2006). Effects of Different treatments of salicylic acid on heat tolerance, chlorophyll fluorescence, and antioxidant enzyme activity in seedlings of Cucumis sativa L. Plant Growth Regul. 48, 127-135. doi: 10.1007/s10725-005-5482-6

Shi, W. M., Muramoto, Y., Ueda, A., and Takabe, T. (2001). Cloning of peroximal ascorbate peroxidise gene from barley and enhanced thermotolerance by overexpressing in Arabidopsis thaliana. Gene 273, 23-27. doi: 10.1016/S03781119(01)00566-2

Shinozaki, K., Yamaguchi-Shinozaki, K., and Seki, M. (2003). Regulatory network of gene expression in the drought and cold stress responses. Curr. Opin. Plant Biol. 6, 410-417. doi: 10.1016/S1369-5266(03)00092-X

Singh, I., and Shono, M. (2005). Physiological and molecular effects of 24epibrassinolide, a brassinosteroid on thermotolerance of tomato. Plant Growth Regul. 47, 111-119. doi: 10.1007/s10725-005-3252-0

Snider, J. L., Oosterhuis, D. M., Skulman, B. W., and Kawakami, E. M. (2009). Heat stress-induced limitations to reproductive success in Gossypium hirsutum. Physiol. Plant 137, 125-138. doi: 10.1111/j.1399-3054.2009.01266.x

Sohn, S. O., and Back, K. (2007).Transgenic rice tolerant to high temperature with elevated contents of dienoic fatty acids. Biol. Plant. 51, 340-342. doi: 10.1007/s10535-007-0067-z

Somersalo, S., Kyei-Boahen, S., and Pehu, E. (1996). Exogenous glycine betaine application as a possibility to increase low temperature tolerance of crop plants. Nord. Jordbruk. 78, 10. 
Song, S. Y., Chen, Y., Chen, J., Dai, X. Y., and Zhang, W. H. (2011). Physiological mechanisms underlying OsNAC5-dependent tolerance of rice plants to abiotic stress. Planta 234, 331-345. doi: 10.1007/s00425-011-1403-2

Srinivasan, A., Saxena, N. P., and Johansen, C. (1999). Cold tolerance during early reproductive growth of chickpea (Cicer arietinum L): genetic variation in gamete development and function. Field Crops Res. 60, 209-222. doi: 10.1016/S0378-4290(98)00126-9

Starck, Z., Niemyska, B., Bogdan, J., and Tawalbeh. (2000). RNA Response of tomato plants to chilling stress in association with nutrient or phosphorus starvation. Plant Soil 226, 99-106. doi: 10.1023/A:1026497104077

Streb, P., and Feierabend, J. (1999). Significance of antioxidants and electron sinks for the cold-hardening-induced resistance of winter rye leaves to photo-oxidative stress. Plant Cell Environ. 22, 1225-1237. doi: 10.1046/j.13653040.1999.00482.x

Sugio, A., Dreos, R., Aparicio, F., and Maule, A. J. (2009). The cytosolic protein response as a sub component of the wider heat shock response in Arabidopsis. Plant Cell 21, 642-654. doi: 10.1105/tpc.108.062596

Sung, D. Y., Kaplan, F., Lee, K. J., and Guy, C. L. (2003). Acquired tolerance to temperature extremes. Trends Plant Sci. 8, 179-187. doi: 10.1016/S13601385(03)00047-5

Suzuki, N., Koussevitzky, S., Mittler, R., and Miller, G. (2011). ROS and redox signalling in the response of plants to abiotic stress. Plant Cell Environ. 14, 691-699. doi: 10.1016/j.pbi.2011.07.014

Suzuki, N., and Mittler, R. (2006). Reactive oxygen species and temperature stresses: a delicate balance between signalling and destruction. Physiol. Planta 126, 45-51. doi: 10.1111/j.0031-9317.2005.00582.x

Svensson, J., Ismail, A., Palva, E. T., and Close, T. J. (2002). "Dehydrins," in Cell and Molecular Responses to Stress, eds K. B. Storey and J. B. Storey (Amsterdam: Elsevier Science), 155-171.

Takahashi, S., and, Murata, N. (2008). How do environmental stresses acclelerate photoinhibition? Trends Plant Sci. 13, 178-182. doi: 10.1016/j.tplants.2008.01.005

Tambussi, E. A., Bartoli, C. G., Guiamet, J. J., Beltrano, J., and Araus, J. L. (2004). Oxidative stress and photo damage at low temperatures in soybean (Glycine max L. Merr.) leaves. Plant Sci.167, 19-26. doi: 10.1016/j.plantsci.2004.02.018

Tan, W., Meng, Q. W., Brestic, M., Olsovska, K., and Yang, X. (2011). Photosynthesis is improved by exogenous calcium in heat-stressed tobacco plants. J. Plant Physiol. 168, 2063-2071. doi: 10.1016/j.jplph.2011.06.009

Tausz, M., Sircelj, H., and Grill, D. (2004). The glutathione system as a stress marker in plant ecophysiology: is a stress-response concept valid? J. Exp. Bot. 55, 1955-1962. doi: 10.1093/jxb/erh194

Teplova, I. R., Farkhutdinov, R. G., Mitrichenko, A. N., Ivanov, I. I., Veselov, S. Y., Valcke, R. L., et al. (2000). Response of tobacco plants transformed with the ipt gene to elevated temperature. Russ. J. Plant Physiol. 47, 367-369.

Thakur, P., Kumar, S., Malik, J. A., Berger, J. D., and Nayyar, H. (2010). An overview: cold stress effects on reproductive development in grain crops. Environ. Exp. Bot. 67, 429-443. doi: 10.1016/j.envexpbot.2009.09.004

Theocharis, A., Clemente, C., and Barka, E. A. (2012). Physiological and molecular changes in plants grown at low temperatures. Planta 235, 1091-1105. doi: 10.1007/s00425-012-1641-y

Thomashow, M. F. (1999). Plant cold acclimation. Ann. Rev. Plant Physiol. Plant Mol. Biol. 50, 571-599. doi: 10.1146/annurev.arplant.50.1.571

Tikhomirova, E. V. (1985). Changes of nitrogen metabolism in millet at elevated temperatures. Field Crops Res. 11, 259-264. doi: 10.1016/0378-4290(85)90107-8

Torres, A. M., Avila, C. M., Stoddard, F. L., and Cubero, J. I. (2011). "Faba bean," in Genetics, Genomics and Breeding of Cool Season Grain Legumes (Genetics, Genomics and Breeding in Crop Plants), eds M. P. de la Vega, A. M. Torres, J. I. Cubero, and C. Kole (New Hamsphire: Science Pubs), 50-97.

Torres, M. A., Dangl, J. L., and Jones, J. D. G. (2002). Arabidopsis gp91 ${ }^{\text {phox }}$ homologues Atrbohd and Atrbohf are required for accumulation of reactive oxygen intermediates in the plant defense response. Proc. Natl. Acad. Sci. U.S.A. 99, 517-522. doi: 10.1073/pnas.012452499

Tsonev, T., Velikova, V., Georgieva, K., Hyde, P. F., and Jones, H. G. (2003). Low temperature enhances photosynthetic down-regulation in French bean (Phaseolus vulgaris L.) plants. Ann. Bot. 91, 343-352. doi: 10.1093/aob/mcg020

Turan, O., and Ekmekci, Y. (2011). Activities of photosystem II and antioxidant enzymes in chickpea (Cicer arietinum L.) cultivars exposed to chilling temperatures. Acta Physiol. Plant 33, 67-78. doi: 10.1007/s11738-010-0517-7
Tuteja, N., Sahoo, R. K., Garg, B., and Tuteja, R. (2013). OsSUV3 dual helicase functions in salinity stress tolerance by maintaining photosynthesis and antioxidant machinery in rice (Oryza sativa L. cv. IR64). Plant J. 76, 115-127. doi: 10.1111/tpj.12277

Tuteja, N., Tiburcio, A. F., Gill, S. S., and Tuteja, R. (2012). Improving Crop Resistance to Abiotic Stress, 1st Edn. New Hamsphire: Wiley-VCH Verlag GmbH \& Co. KGaA.

Uchida, A., Jagendorf, A. T., Hibino, T., and Takabe, T. (2002). Effects of hydrogen peroxide and nitric oxide on both salt and heat stress tolerance in rice. Plant Sci. 163, 515-523. doi: 10.1016/S0168-9452(02)00159-0

Upreti, K. K., and Murti, G. S. R. (2004). Effects of brassinosteroids on growth, nodulation, phytohormone content and nitrogenase activity in French bean under water stress. Biol. Plant 48, 407-411. doi: 10.1023/B:BIOP.0000041094.13 $342.1 \mathrm{~b}$

Vadez, V., Berger, J. D., Warkentin, T., Asseng, S., Kumar, P. R., Rao, K. P. C., et al. (2012). Adaptation of grain legumes to climate change: a review. Agron. Sustain. Dev. 32, 31-44. doi: 10.1007/s13593-011-0020-6

Vardhini, B. V, and Rao, S. S. R. (2003). Amelioration of osmotic stress by brassinosteroids on seed germination and seedling growth of three varieties of sorghum. Plant Growth Regul. 41, 25-31. doi: 10.1023/A:10273035 18467

Vigh, L., Torok, J., Balogh, G., Glatz, A., and Piotto, S. (2007). Membrane-regulated stress response: a theoretical and practical approach. Adv. Exp. Med. Biol. 594, 114-131. doi: 10.1007/978-0-387-39975-1_11

Vinocur, B., and Altman, A. (2005). Recent advances in engineering plant tolerance to abiotic stress: achievements and limitations. Curr. Opin. Biotechnol. 16, 123-132. doi: 10.1016/j.copbio.2005.02.001

Wahid, A., Gelani, S., Ashraf, M., and Foolad, M. R. (2007). Heat tolerance in plants: an overview. Environ. Exp. Bot. 61, 199-223. doi: 10.1016/j.envexpbot.2007.05.011

Wang, B., Vinocur, O., and Altman, A. S. (2004). Role of plant heat-shock proteins and molecular chaperones in the abiotic stress response. Trends Plant Sci. 9 , 244-252. doi: 10.1016/j.tplants.2004.03.006

Wang, H., Feng, T., Peng, G. X., Yan, M., Zhou, P., and Tang, X. (2009a) Ameliorative effects of brassinosteroids on excess manganese-induced oxidative stress in Zea mays L. leaves. Agric. Sci. China 8, 1063-1074. doi: 10.1016/S16712927(08)60314-4

Wang, L. J., Fan, L., Loescher, W., Duan, W., Liu, G. J., Cheng, J. S., et al. (2010). Salicylic acid alleviates decreases in photosynthesis under heat stress and accelerates recovery in grapevine leaves. BMC Plant Biol. 10:34. doi: 10.1186/1471-2229-10-34

Wang, L. J., and Li, S. H. (2006). Salicylic acid-induced heat or cold tolerance in relation to $\mathrm{Ca}^{2+}$ homeostasis and antioxidant systems in young grape plants. Plant Sci. 170, 685-694. doi: 10.1016/j.plantsci.2005.09.005

Wang, P., Duan, W., Takabayashi, A., Endo, T., Shikanai, T., and Ye, J. Y. (2006). Chloroplastic NAD $(\mathrm{P}) \mathrm{H}$ dehydrogenase in tobacco leaves functions in alleviation of oxidative damage caused by temperature stress. Plant Physiol. 141, 465-474. doi: 10.1104/pp.105.070490

Wang, W. B., Kim, Y. H., Lee, H. S., Kim, K. Y., Deng, X. P., and Kwak, S. S. (2009b). Differential antioxidation activities in two alfalfa cultivars under chilling stress. Plant Biotechnol. Rep. 3, 301-307. doi: 10.1007/s11816-009-0102-y

Wang, W., Vinocur, B., and Altman, A. (2003). Plant responses to drought, salinity and extreme temperatures: towards genetic engineering for stress tolerance. Planta 218, 1-14. doi: 10.1007/s00425-003-1105-5

Willits, D. H., and Peet, M. M. (2001). Measurement of chlorophyll fluorescence as a heat stress indicator in tomato: laboratory and greenhouse comparison. J. Am. Soc. Hort. Sci. 126, 188-194.

Wilson, R. A., Sangha, M. K., Banga, S. S., Atwal, A. K., and Gupta, S. (2014). Heat stress tolerance in relation to oxidative stress and antioxidants in Brassica juncea. J. Environ. Biol. 35, 383-387.

Wormuth, D., Heiber, I., Shaikali, J., Kandlbinder, A., Baier, M., and Dietz, K. J. (2007). Redox regulation and antioxidative defence in Arabidopsis leaves viewed from a systems biology perspective. J. Biotechnol. 129, 229-248. doi: 10.1016/j.jbiotec.2006.12.006

Xin, Z., and Browse, J. (1998). eskimol mutants of Arabidopsis are constitutively freezing-tolerant. Proc. Natl. Acad. Sci. U.S.A. 95, 7779-7804. doi: 10.1073/pnas.95.13.7799

Xu, S., Li, J., Zhang, X., Wei, H., and Cui, L. (2006). Effects of heat acclimation pre-treatment on changes of membrane lipid peroxidation, 
antioxidant metabolites, and ultrastructure of chloroplasts in two cool-season turf grass species under heat stress. Environ. Exp. Bot. 56, 274-285. doi: 10.1016/j.envexpbot.2005.03.002

Yadav, R. S., Hash, C. T., Bidinger, F. R., Devos, K. M., and Howarth, C. J. (2004).Genomic regions associated with grain yield and aspects of postflowering drought tolerance in pearl millet across environments and tester background. Euphytica 136, 265-277. doi: 10.1023/B:EUPH.0000032711.34599.3a

Yadav, S. K. (2010).Cold stress tolerance mechanisms in plants. Agron. Sustain. Dev. 30, 515-527. doi: 10.1051/agro/2009050

Yan, J., Tsuichihara, N., Etoh, T., and Iwai, S. (2007). Reactive oxygen species and nitric oxide are involved in ABA inhibition of stomatal opening. Plant Cell Environ. 30, 1320-1325. doi: 10.1111/j.1365-3040.2007.01711.x

Yang, F., Jensen, J. D., Svensson, B., Jorgensen, H. J., Collinge, D. B., and Finnie, C. (2012). Secretomics identifies Fusarium graminearum proteins involved in the interaction with barley and wheat. Mol. Plant Pathol. 13, 445-453. doi: 10.1111/j.1364-3703.2011.00759.x

Yang, J. D., Yun, J. Y., Zhang, T. H., and Zhao, H. L. (2006). Presoaking with nitric oxide donor SNP alleviates heat shock damages in mung bean leaf discs. Bot. Stud. 47, 129-136.

Yang, X., Liang, Z., and Lu, C. (2005). Genetic engineering of the biosynthesis of glycine betaine enhances photosynthesis against high temperature stress in transgenic tobacco plants. Plant Physiol. 138, 2299-2309. doi: 10.1104/pp.105.063164

Yang, X., Yang, Y. N., Xue, L. J., Zou, M. J., Liu, J. Y., and Chen, F. (2011). Rice ABI5-Like1 regulates abscisic acid and auxin responses by affecting the expression of ABRE-containing genes. Plant Physiol. 156, 1397-1409. doi: 10.1104/pp.111.173427

Yordanova, R., and Popova, L. (2007). Effect of exogenous treatment with salicylic acid on photosynthetic avtivity and antioxidant capacity of chilled wheat plants. Gen. Appl. Plant Physiol. 33, 155-170.

Yoshimura, K., Miyao, K., Gaber, A., Takeda, T., Kanboshi, H., Miyasaka, H., et al. (2004). Enhancement of stress tolerance in transgenic tobacco plants overexpressing Chlamydomonas glutathione peroxidise in chloroplasts or cytosol. Plant J. 37, 21-33. doi: 10.1046/j.1365-313X.2003.01930.x

Yu, J. Q., Huang, L. F., Hu, W. H., Zhou, Y. H., Mao, W. H., Ye, S. F., et al. (2004). A role for brassinosteroids in the regulation of photosynthesis in Cucumis sativus. J. Exp. Bot. 55, 1135-1143. doi: 10.1093/jxb/erh124

Yuan, Z. C., Haudecoeur, E., Faure, D., Kerr, K. F., and Nester, E. W. (2008). Comparative transcriptome analysis of Agrobacterium tumefaciens in response to plant signal salicylic acid, indole-3-acetic acid and gammaamino butyric acid reveals signalling cross-talk and Agrobacterium-plant co-evolution. Cell Microbiol. 10, 2339-2354. doi: 10.1111/j.1462-5822.2008. 01215.x

Zhang, F., Wang, Z., Huang, Q. S., Huang, L. P., and Yang, Q. (2010). Cloning and characterization of a PGIP-Encoding gene from Solanum torvurn. Agri. Sci. China 9, 921-927. doi: 10.1016/S1671-2927(09)60172-3
Zhang, J. H., Wang, L. J., Pan, Q. H., Wang, Y. Z., Zhan, J. C., and Huang, W. D. (2008). Accumulation and subcellular localization of heat shock proteins in young grape leaves during cross-adaptation to temperature stresses. Sci. Horti. 117, 231-240. doi: 10.1016/j.scienta.2008.04.012

Zhang, L., Wang, Y., Zhao, L., Shi, S., and Zhang, L. (2006). Involvement of nitric oxide in light-mediated greening of barley seedlings. J. Plant Physiol. 163, 818-826. doi: 10.1016/j.jplph.2005.07.011

Zhao, J., Li, S., Jiang, T., Liu, Z., and Zhang, W. (2012). Chilling stress- the key predisposing factor for causing Alternaria alternata infection and leading to cotton (Gossypium hirsutum 1.) leaf senescence. PLoS ONE 7:e36126. doi: 10.1371/journal.pone.0036126

Zhao, J., Sun, Z., Zheng, J., Guo, X., Dong, Z., Huai, J., et al. (2009).Cloning and characterization of a novel CBL-interacting protein kinase from maize. Plant Mol. Biol. 69, 661-674. doi: 10.1007/s11103-008-9445-y

Zhao, Y., Aspinall, D., and Paleg, L. G. (1992). Protection of Membrane Integrity in Medicago sativa L. by glycinebetaine against the effects of freezing. J. Plant Physiol. 140, 541-543. doi: 10.1016/S0176-1617(11)80785-6

Zhou, J., Wang, J., Shi, K., Xia, X. J., Zhou, Y. H., and Yu, J. Q. (2012). Hydrogen peroxide is involved in the cold acclimation-induced chilling tolerance of tomato plants. Plant Physiol. Biochem. 60, 141-149. doi: 10.1016/j.plaphy.2012. 07.010

Zhu, J. J., Li, Y. R., and Liao, J. X. (2013). Involvement of anthocyanins in the resistance to chilling-induced oxidative stress in Saccharum officinarum L. leaves. Plant Physiol. Biochem. 73, 427-433. doi: 10.1016/j.plaphy.2013.07.008

Zhu, J., Verslues, P. E., Zheng, X., Lee, B. H., Zhan, X., Manabe, Y., et al. (2005). HOS10 encodes an R2R3-type MYB transcription factor essential for cold acclimation in plants. Proc. Natl. Acad. Sci. U.S.A. 102, 9966-9971. doi: $10.1073 /$ pnas.0503960102

Conflict of Interest Statement: The authors declare that the research was conducted in the absence of any commercial or financial relationships that could be construed as a potential conflict of interest.

Received: 14 November 2014; accepted: 09 February 2015; published online: 17 March 2015.

Citation: Awasthi R, Bhandari $K$ and Nayyar $H$ (2015) Temperature stress and redox homeostasis in agricultural crops. Front. Environ. Sci. 3:11. doi: 10.3389/fenvs. 2015.00011

This article was submitted to Environmental Toxicology, a section of the journal Frontiers in Environmental Science.

Copyright (C) 2015 Awasthi, Bhandari and Nayyar. This is an open-access article distributed under the terms of the Creative Commons Attribution License (CC BY). The use, distribution or reproduction in other forums is permitted, provided the original author(s) or licensor are credited and that the original publication in this journal is cited, in accordance with accepted academic practice. No use, distribution or reproduction is permitted which does not comply with these terms. 